\title{
The soluble pattern recognition receptor PTX3 links humoral innate and adaptive immune responses by helping marginal zone B cells
}

\author{
Alejo Chorny, ${ }^{1}$ Sandra Casas-Recasens, ${ }^{1}$ Jordi Sintes,${ }^{5}$ Meimei Shan, ${ }^{1}$ Nadia Polentarutti, ${ }^{6}$ \\ Ramón García-Escudero, ${ }^{7}$ A. Cooper Walland, ${ }^{1}$ John R. Yeiser, ${ }^{1}$ Linda Cassis, ${ }^{5}$ Jorge Carrillo,, 16 \\ Irene Puga, ${ }^{5}$ Cristina Cunha, ${ }^{8,9}$ Hélder Bastos, ${ }^{8,9,10}$ Fernando Rodrigues, ${ }^{8,9}$ João F. Lacerda, ${ }^{11,12}$ \\ António Morais, ${ }^{10}$ Rebeca Dieguez-Gonzalez, ${ }^{1}$ Peter S. Heeger, ${ }^{1,2}$ Giovanni Salvatori, ${ }^{13}$ \\ Agostinho Carvalho, ${ }^{8,9}$ Adolfo Garcia-Sastre, ${ }^{3}$ J. Magarian Blander, ${ }^{1,4}$ Alberto Mantovani, ${ }^{6,14}$ \\ Cecilia Garlanda, ${ }^{6,14}$ and Andrea Cerutti ${ }^{1,5,15}$
}

\author{
'Department of Medicine, Immunology Institute, ${ }^{2}$ Translational Transplant Research Center and Department of Medicine, ${ }^{3}$ Department of Microbiology, and ${ }^{4}$ Tisch \\ Cancer Institute, Icahn School of Medicine at Mount Sinai, New York, NY 10029 \\ ${ }^{5}$ Program for Inflammatory and Cardiovascular Disorders, Institut Hospital del Mar d'Investigacions Mèdiques, 08003 Barcelona, Spain \\ ${ }^{6}$ Istituto di Ricovero e Cura a Carattere Scientifico Humanitas Clinical and Research Hospital, Rozzano, 20089 Milan, Italy \\ ${ }^{7}$ Molecular Oncology Unit, Centro de Investigaciones Energéticas, Medioambientales, y Tecnológicas, 28040 Madrid, Spain \\ ${ }^{8}$ Life and Health Sciences Research Institute, School of Health Sciences and ${ }^{9}$ PT Government Associate Laboratory, Braga/Guimarães, Life and Health Sciences \\ Research Institute /3B's, University of Minho, 4710-057 Braga, Portugal \\ ${ }^{10}$ Serviço de Pneumologia, Centro Hospitalar São João, Faculdade de Medicina, Universidade do Porto, 4200-319 Porto, Portugal \\ "Instituto de Medicina Molecular, Faculdade de Medicina da Universidade de Lisboa, 1649-028 Lisboa, Portugal \\ ${ }^{12}$ Hospital de Santa Maria, 1649-035 Lisboa, Portugal \\ ${ }^{13}$ Sigma-Tau Industrie Farmaceutiche Riunite, Pomezia, 00040 Roma, Italy \\ ${ }^{14}$ Humanitas University, Rozzano, 20089 Milan, Italy \\ ${ }^{15}$ Catalan Institute for Research and Advanced Studies, 08003 Barcelona, Spain \\ ${ }^{16}$ Institut de Recerca de la Sida IrsiCaixa, Hospital Universitari Germans Trias i Pujol, 08916 Badalona, Barcelona, Spain
}

Pentraxin 3 (PTX3) is a fluid-phase pattern recognition receptor of the humoral innate immune system with ancestral antibody-like properties but unknown antibody-inducing function. In this study, we found binding of PTX3 to splenic marginal zone (MZ) B cells, an innate-like subset of antibody-producing lymphocytes strategically positioned at the interface between the circulation and the adaptive immune system. PTX3 was released by a subset of neutrophils that surrounded the splenic MZ and expressed an immune activation-related gene signature distinct from that of circulating neutrophils. Binding of PTX3 promoted homeostatic production of IgM and class-switched IgG antibodies to microbial capsular polysaccharides, which decreased in PTX3-deficient mice and humans. In addition, PTX3 increased IgM and IgG production after infection with blood-borne encapsulated bacteria or immunization with bacterial carbohydrates. This immunogenic effect stemmed from the activation of MZ B cells through a neutrophil-regulated pathway that elicited class switching and plasmablast expansion via a combination of T cell-independent and T cell-dependent signals. Thus, PTX3 may bridge the humoral arms of the innate and adaptive immune systems by serving as an endogenous adjuvant for MZ B cells. This property could be harnessed to develop more effective vaccines against encapsulated pathogens.

\section{INTRODUCTION}

Innate humoral immunity generates a first line of defense through the secretion of collectin, ficolin, Pentraxin (PTX),

Correspondence to Andrea Cerutti: acerutti@imim.es

Abbreviations used: AID, activation-induced cytidine deaminase; APRIL, a proliferation-inducing ligand; BAFF, B cell activation factor of the TNF family; BAL, bronchoalveolar lavage; BCR, B cell receptor; CPS, capsular polysaccharide; CRP, C-reactive protein; CSR, class-switch recombination; FO B cell, follicular B cell; GSEA, gene set enrichment analysis; HPRT, hypoxanthine-guanine phosphoribosyl transferase; IFA immunofluorescence analysis; ILC, innate lymphoid cell; MMP9, matrix metalloprotease 9; MZ, marginal zone; NBh, B helper neutrophil; NC, circulating neutrophil; $\mathrm{PB}$, plasmablast; $\mathrm{PC}$, plasma cell; PTX, pentraxin; $\mathrm{RRT}-\mathrm{PCR}$, quantitative real-time PCR; SHM, somatic hypermutation; SNP, single nucleotide polymorphism; SP, Streptococcus pneumoniae; TD, T cell dependent; TI, T cell independent. and complement proteins by nonspecific myeloid and somatic cells (Bottazzi et al., 2010). Adaptive humoral immunity develops later and involves the release of Igs by specific B cells (Victora and Nussenzweig, 2012). Besides recognizing defined antigenic epitopes, Ig molecules interact with both humoral and cellular components of the innate immune system to maximize the clearance of intruding microbes (Holmskov et al., 2003; Ehrenstein and Notley, 2010).

O 2016 Chorny et al. This article is distributed under the terms of an Attribution-Noncommercial-Share

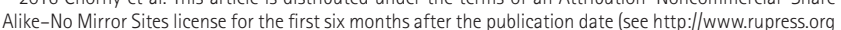
Alike-No Mirror Sites license for the first six months after the publication date (see http://www.rupress.org
lterms). After six months it is available under a Creative Commons License (Attribution-NoncommercialShare Alike 3.0 Unported license, as described at http://creativecommons.org/licenses/by-nc-sa/3.0/). 
PTXs are comprised of short and long family members that include C-reactive protein (CRP) and PTX3, respectively (Bottazzi et al., 2010). PTX3 recognizes well defined sets of bacteria and fungi and promotes both phagocytosis and immune activation by interacting with complement proteins, ficolins, and powerful $\operatorname{IgG}$ receptors (Fc $\gamma \mathrm{Rs}$ ) expressed on innate effector cells (Garlanda et al., 2002; Ma et al., 2009; Jaillon et al., 2014). Although DCs and macrophages up-regulate PTX3 expression in response to microbial signals from TLRs, neutrophils rapidly discharge preformed PTX3 from secondary granules in response to immune signals from cytokines (Jaillon et al., 2007).

Given their ability to recognize restricted sets of microbial molecular patterns, PTXs are viewed as ancestors of antibodies produced by follicular B cells (FO B cells; Bottazzi et al., 2010). These adaptive lymphocytes undergo antibody gene diversification through somatic hypermutation (SHM) and class-switch recombination (CSR) after establishing antigen-driven cognate interactions with $\mathrm{CD}^{+} \mathrm{T}$ cells in response to protein antigens (Victora and Nussenzweig, 2012). SHM provides a structural correlate for the selection of antibodies with higher affinity for antigen, whereas CSR modulates the antibody effector functions by replacing IgM and $\operatorname{IgD}$ with $\operatorname{IgG}$, $\operatorname{IgA}$, or $\operatorname{IgE}$ antibodies (Honjo et al., 2002). Highly mutated memory B cells and antibody-secreting plasma cells (PCs) emerging from this T cell-dependent (TD) pathway provide long-term humoral protection (McHeyzer-Williams et al., 2012).

FO B cells need several days to mount a protective response and, thus, are complemented by splenic marginal zone (MZ) B cells strategically positioned between the circulation and the immune system. MZ B cells integrate signals from B cell receptors (BCRs), complement receptors, andTLRs to rapidly mount largely unmutated IgM and IgG responses against carbohydrate and lipid antigens through a $\mathrm{T}$ cell-independent (TI) pathway characterized by extrafollicular expansion of short-lived plasmablasts (PBs; Guinamard et al., 2000; Martin et al., 2001). The activation of this TI pathway further involves cytokines produced by DCs, macrophages, innate lymphoid cells (ILCs), and neutrophils (Balázs et al., 2002; Puga et al., 2012; Xu et al., 2012; Giordano et al., 2014; Magri et al., 2014).

Because of their quick kinetics but limited specificity, splenic MZ B cells are defined as innate-like lymphocytes along with peritoneal and splenic B-1 cells (Cerutti et al., 2013). Besides enhancing antimicrobial protection, antibodies from innate-like B cells regulate tissue homeostasis by interacting with complement, collectins, and ficolins (Ochsenbein et al., 1999; Holmskov et al., 2003; Ehrenstein and Notley, 2010; Panda et al., 2013). Though unable to bind antibodies, some PTX family members such as CRP activate PCs through a mechanism involving FcyRs (Yang et al., 2007). Thus, we hypothesized that PTX3 stimulates antibody production in addition to deploying antibody-like functions.

We found abundant PTX3 expression in a unique subset of neutrophils that inhabited splenic peri-MZ areas and expressed a gene signature that reflected local immune activation. PTX3 from splenic neutrophils bound to MZ B cells by delivering $F c \gamma R$-independent signals that triggered CSR from $\operatorname{IgM}$ to IgG. These signals enhanced IgM and IgG responses to blood-borne encapsulated bacteria or capsular polysaccharides (CPS) by promoting MZ B cell differentiation into extrafollicular PBs through a neutrophil-regulated pathway that involved TI in addition to TD signals. Thus, besides possessing antibody-like properties, PTX3 deploys antibody-inducing functions that could be harnessed for the development of more effective vaccines against encapsulated pathogens.

\section{RESULTS}

\section{PTX3 expression is elevated in B helper neutrophil cells (NBh cells)}

$\mathrm{NBh}$ cells are B cell helper neutrophils regulated by commensal microbial signals and GM-CSF, a cytokine released by splenic ILCs (Puga et al., 2012; Magri et al., 2014). When exposed to GM-CSF, circulating neutrophils (NC cells) acquire some of the phenotypic and functional properties of NBh cells (Magri et al., 2014; Seifert et al., 2015). To further elucidate the relationship between circulating and splenic neutrophils, we comparatively studied human NC and NBh cells by flow cytometry, light microscopy, and global transcriptome analysis.

Despite being morphologically similar to NC cells, NBh cells showed a more pronounced activated phenotype, which featured increased expression of the adhesion molecules CD11b (Mac-1) and CD177 (NB1), as well as reduced expression of the IgG receptor CD16 (Fc $\gamma$ RIII) and the adhesion molecule CD62L (L-selectin; Fig. S1, A-C). Consistent with their derivation from circulating precursors, NBh cells shared the expression of 16,803 transcripts with $\mathrm{NC}$ cells (Fig. 1 A). At the same time, NBh cells differed from NC cells with respect to the expression of 3,264 transcripts, raising the possibility that $\mathrm{NBh}$ cells emerge from NC cells receiving conditioning signals from the splenic microenvironment. Accordingly, gene ontology analysis ascribed 1,227 transcripts enriched in NBh cells to functional categories related to neutrophil activation and immune defense, whereas 2,037 transcripts down-regulated in NBh cells related to neutrophil apoptosis, protein catabolism, and various signaling events (Fig. 1 B).

Among the 1,227 transcripts enriched in NBh cells, we identified transcripts for the activation-related receptors CD69 and CD177, the prosurvival proteins IкB $\alpha$,

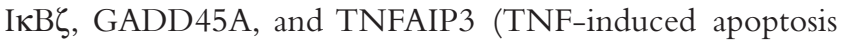
inhibition protein 3), the transcriptional activators FOSB, FOSL1, and EGR-1 (early growth response 1), and various antimicrobial factors and immune mediators involved in the recruitment and activation of neutrophils, including the complement subunits $\mathrm{C} 1 \mathrm{q}$ and $\mathrm{C} 4 \mathrm{BPA}$, the $\mathrm{C} 1 \mathrm{q}-$ binding opsonin PTX3, the immunostimulating cytokines IL-1 $\beta$ and EDN-1 (endothelin 1), and the neutrophil-attracting chemokines CXCL8 and CXCL2 (Fig. 1 C, Fig. S1 D, and Table S5). 
A

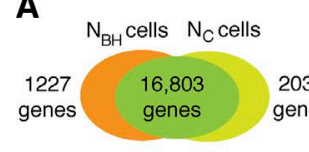

$\mathrm{FC}>1.2$

Adjusted $p$ value $<0.01$

$\mathrm{N}_{\mathrm{BH}}$ cells $\mathrm{N}_{\mathrm{C}}$ cells
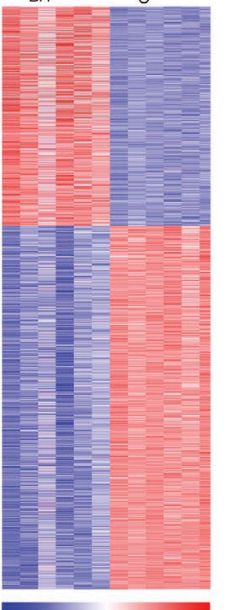

$\begin{array}{lll}-2.0 & 0.0 & 2.0\end{array}$

C

Z-scor

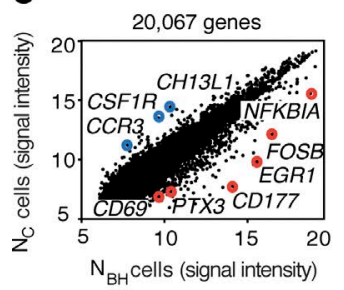
nes
B

Functional categories up-regulated $\square$ or $\square$ down-regulated in $\mathrm{N}_{\mathrm{BH}}$ cells compared to $\mathrm{N}_{\mathrm{C}}$ cells Positive regulation of immunity DNA packaging 22 Defense response Leukocyte activation 31 Inflammation 37 Regulation of apoptosis 65 T cell activation 19 Monosaccharide metabolism 45

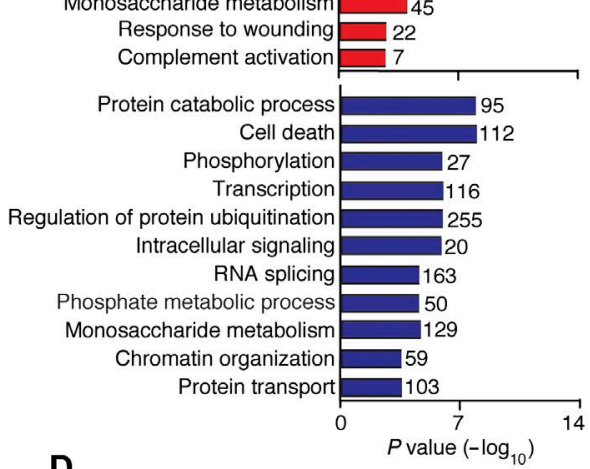

D Top 10 genes similarly up-regulated in $\mathrm{N}_{\mathrm{BH}}$ cells and GM-CSF-activated $\mathrm{N}_{\mathrm{C}}$ cells

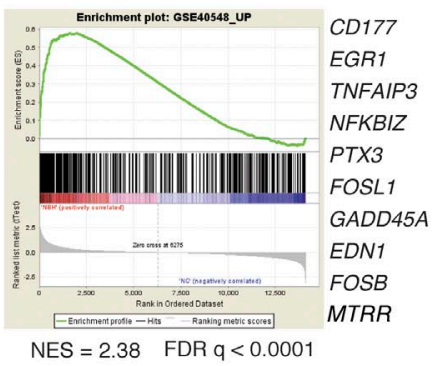

E

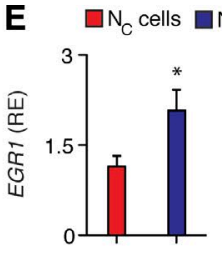

$\mathrm{N}_{\mathrm{BH}}$ cells

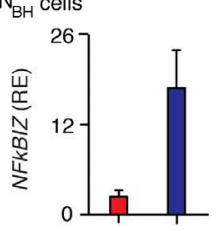

F
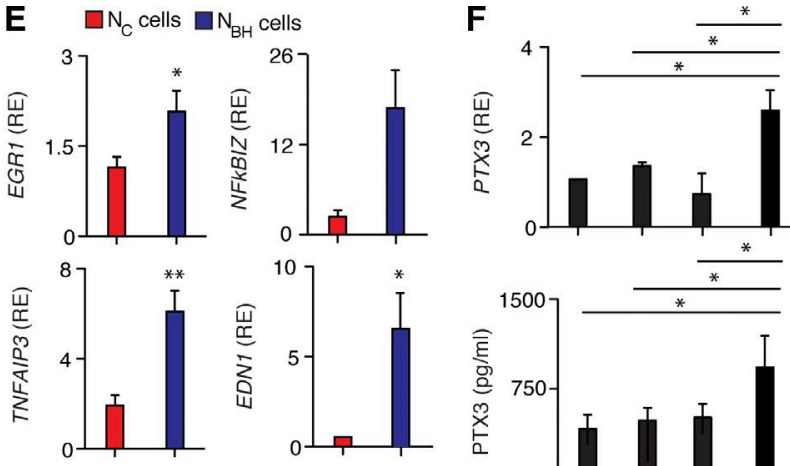

G

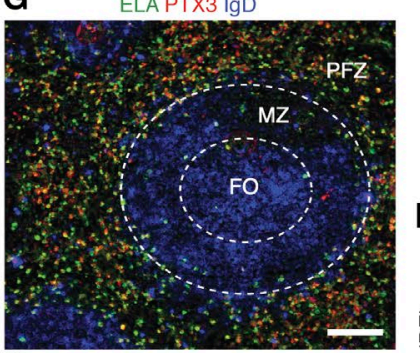

H

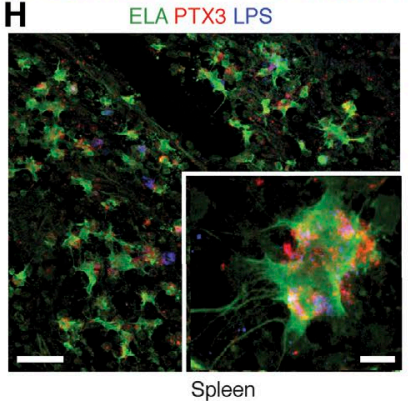

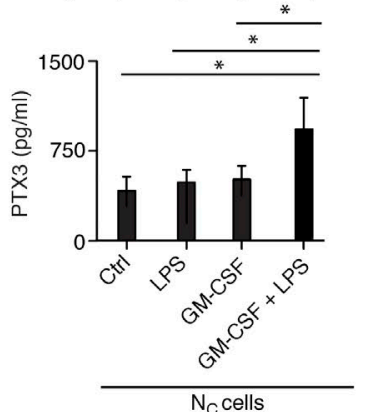

I J

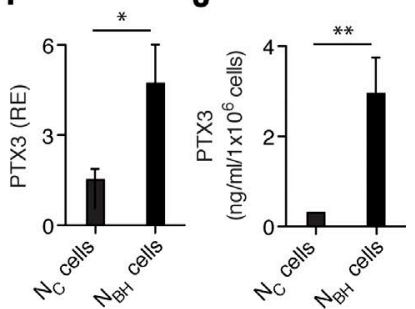

Figure 1. PTX3 is released by NBh cells expressing an immune activation-related gene signature. (A) Microarray analysis of human NC and NBh cells. The Venn diagram summarizes comparably and differentially expressed genes, whereas the heat map provides a global view of differentially expressed genes. Colors correspond to significant fold change (FC) expression. Red, high expression; blue, low expression. (B) Gene ontology analysis showing the top 10 biological processes up-regulated (red) and down-regulated (blue) in human NBh cells compared with NC cells. Numbers indicate genes. (C) Scatter plot illustrating gene expression signal intensity in human NC and NBh cells. Circles indicate some of the top differentially expressed genes. (D) GSEA comparing genes expressed by NBh cells and GM-CSF-activated NC cells. Normalized enrichment score (NES) indicates correlation between individual gene sets. Positive correlation, NES $>0$ (red bars); negative correlation, NES $<0$ (blue bars). The top 10 genes similarly up-regulated in NBh cells and GM-CSF-treated

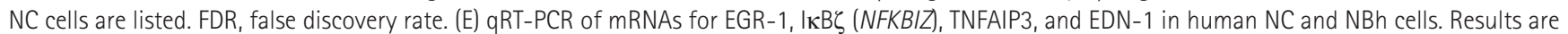
normalized to mRNA for $\beta$-actin and presented as relative expression (RE) compared with a reference set of NC cells. (F) qRT-PCR of PTX3 mRNA (top) and ELI SA of PTX3 protein (bottom) from human NC cells cultured with or without GM-CSF and/or LPS for $1 \mathrm{~d}$. PTX3 mRNA is normalized to mRNA for $\beta$-actin and presented as relative expression compared with NC cells cultured with medium alone (Ctrl). (G and H) IFA of human spleens stained for elastase (ELA; green), PTX3 (red), and IgD or LPS (blue). FO, follicle; PFZ, perifollicular zone. Bars: (G) $200 \mu \mathrm{m}$; (H) $40 \mu \mathrm{m}$; (H, right inset) $6 \mu \mathrm{m}$. (I and J) qRT-PCR of PTX3 mRNA (I) and ELISA of PTX3 protein (J) from human NC and NBh cells. PTX3 mRNA is normalized to $\beta$-actin mRNA and shown as relative expressions compared with NC cells. ELISA was performed after $2 \mathrm{~d}$ of culture in medium alone. Data show one experiment with six biological replicates for each cell type (A-D), one representative experiment of at least four with similar results $(E-H)$, or two experiments with at least three samples in each experimental group (I and $J)$. Error bars, SEM. ${ }^{*}, \mathrm{P}<0.05 ;{ }^{* *}, \mathrm{P}<0.01$ (two-tailed Student's $t$ test).

Of these gene products, PTX3 combines antibody-like and immunoenhancing properties (Bottazzi et al., 2010) and was thus hypothesized to modulate MZ B cells.

Before testing this possibility, we examined the relationship between PTX3 and GM-CSF through gene set enrichment analysis (GSEA). By comparing up-regulated NBh cell gene products with published datasets from GM-CSF-acti- vated NC cells (Wright et al., 2013), GSEA identified PTX3 within a GM-CSF-related signature that also encompassed transcripts encoding CD177, EGR-1, FOSB, FOSL1, TNF AIP3, EDN-1, IאBל, and GADD45A (Fig. 1 D). Quantitative real-time PCR (qRT-PCR) validated the up-regulation of EGR-1, IкB $\zeta$, TNFAIP3, and EDN-1 in NBh cells (Fig. 1 E). In addition, qRT-PCR and ELISA showed induc- 
tion of PTX3 by GM-CSF in NC cells coexposed to LPS (Fig. $1 \mathrm{~F}$ ), a TLR 4 ligand that reaches the spleen after postnatal mucosal colonization by the microbiota (Puga et al., 2012). Thus, human NBh cells express a distinct transcriptome that includes PTX3, a protein strongly induced by NC cells in response to combined signals from GM-CSF and LPS.

\section{PTX3 from NBh cells binds to MZ B cells}

Given that PTX3 may modulate MZ B cell responses, we performed tissue immunofluorescence analysis (IFA), qRTPCR, and ELISA to elucidate the topography, expression, and release of PTX3 in humans. PTX3 was detected in NBh cells that expressed the neutrophil-specific enzyme elastase and inhabited the perifollicular zone, a splenic area positioned around $\mathrm{IgD}^{\mathrm{lo}} \mathrm{MZ} \mathrm{B}$ cells and communicating with the red pulp through mannose receptor-expressing sinusoids (Fig. $1 \mathrm{G}$ and Fig. S1 E). In agreement with a published study (Puga et al., 2012), some PTX3-expressing NBh cells captured LPS (Fig. $1 \mathrm{H}$ ), a microbial product that cooperates with GM-CSF for the induction of PTX3. Consistent with the presence of both GM-CSF and LPS in the spleen (Puga et al., 2012; Magri et al., 2014), NBh cells contained more transcripts for PTX3 and released more PTX3 than NC cells did (Fig. 1, I and J). Of note, splenic macrophages also expressed PTX3, albeit less than NBh cells (Fig. S1 F).

Given the peri-MZ topography of NBh cells, we reasoned that PTX3 may contribute to the activation of MZ $\mathrm{B}$ cells. Tissue IFA identified areas of PTX3 colocalization with IgD (Fig. 2 A), whereas flow cytometry showed binding of PTX3 to some CD19 ${ }^{+} \mathrm{B}$ cells but not to CD19- cells (Fig. 2 B). The latter include $\mathrm{T}$ cells, which neither interact with nor are altered by PTX3 (Garlanda et al., 2002). Compared with class-switched memory $\operatorname{IgD}^{-} \mathrm{CD} 27^{+} \mathrm{B}$ cells, unswitched $\mathrm{MZ} \operatorname{IgD}{ }^{\mathrm{lo}} \mathrm{CD} 27^{+}$and naive $\operatorname{IgD}{ }^{\text {hi }} \mathrm{CD} 27^{-} \mathrm{B}$ cells showed more binding of fluorochrome-labeled PTX3, which was specifically inhibited by unlabeled PTX3 but not control IgG proteins (Fig. 2, C and D). Of note, PTX3 binding increased upon exposure of MZ B cells to NC cells primed with GM-CSF and LPS or to CpG-rich DNA (Fig. 2, E and F), a TLR9 ligand highly expressed by MZ B cells (Cerutti et al., 2013). Consistent with studies showing activation of the complement cascade by PTX3 and amplification of MZ $\mathrm{B}$ cell responses by complement proteins (Guinamard et al., 2000; Moalli et al., 2010), binding of PTX3 to B cells further increased in the presence of C1q (Fig. 2 G). This observation correlated with IFA data showing PTX3-expressing NBh cells adjacent to $\mathrm{C} 1 \mathrm{q}$-expressing stromal reticular cells in perifollicular areas of the spleen (Fig. $2 \mathrm{H}$ ). Thus, PTX3 is abundantly released by human NBh cells and binds to $\mathrm{MZ}$ and naive $\mathrm{B}$ cells through a mechanism enhanced by the microbial product CpG DNA and the PTX3-binding protein C1q.

\section{PTX3 promotes class switching and antibody production}

We next performed ELISA and standard reverse transcription PCR followed by Southern blotting to establish the B cell-stimulating function of PTX3 in humans. When exposed to PTX3, $\mathrm{IgD}^{+} \mathrm{B}$ cells induced molecular byproducts of CSR from IgM to IgG1, IgG2, and IgG3, including germline I $\gamma 1-\mathrm{C} \gamma 1$, I $\gamma 2-\mathrm{C} \gamma 2$, and I $\gamma 3-\mathrm{C} \gamma 3$ transcripts as well as switch circle I $\gamma 1 / 2-\mathrm{C} \mu$ and $\mathrm{I} \gamma 3-\mathrm{C} \mu$ transcripts (Fig. $2 \mathrm{I}$ ). This induction was associated with transcriptional changes involved in the initiation of CSR and $\mathrm{PB} / \mathrm{PC}$ differentiation (Puga et al., 2012; Magri et al., 2014), including up-regulation of the CSR-inducing enzyme activation-induced cytidine deaminase (AID) and up-regulation of the PB/PC-inducing transcription factor BLIMP-1 (Fig. $2 \mathrm{~J}$ ). Yet, PTX3 enhanced the secretion of class-switched IgG only in the presence of additional signals from BAFF (B cell activation factor of the TNF family) or IL-10 (Fig. $2 \mathrm{~K}$ ), two B cell-stimulating cytokines produced by NBh cells, ILCs, and/or macrophages (Puga et al., 2012; Magri et al., 2014). Similarly, CpG DNA enhanced IgG production in B cells exposed to PTX3 (not depicted). Thus, human NBh cells may use PTX3 to enhance IgG class switching in B cells.

\section{PTX3 binds MZ B cells independently of TLR4 and Fc $\gamma$ Rs}

To elucidate the antibody-inducing function of PTX3 in vivo, we first performed tissue IFA, flow cytometry, and qRT-PCR to define the geography, regulation, and binding mechanisms of PTX3 in WT C57BL/6 mice. $\mathrm{Ly}_{6} \mathrm{G}^{+} \mathrm{CD} 11 \mathrm{~b}^{+}$ NBh cells expressing the matrix metalloprotease 9 (MMP9) inhabited splenic peri-MZ but not follicular areas containing B220 ${ }^{+} \mathrm{IgM}^{+}$B cells (Fig. 3,A and B). Compared with NC cells or bone marrow neutrophils, NBh cells expressed an activated phenotype that included decreased expression of CD62L along with increased expression of the adhesion molecule CD54 (ICAM-1), the costimulatory molecule CD86 (B7-2), and the early activation molecule CD69 (not depicted). Similar to human NBh cells (Puga et al., 2012), mouse NBh cells were also enriched in transcripts for the B cell-stimulating factors BAFF, APRIL (a proliferation-inducing ligand), and CD40 ligand (CD40L) but not IL-6 or IL-10 (Fig. 3 C).

Consistent with the involvement of TLR signals in splenic neutrophil homeostasis (Puga et al., 2012), mouse NBh cells up-regulated PTX3 in response to TLR4 signals from LPS (Fig. 3 D). Conversely, PTX3 was decreased in TLR signaling-deficient $M y d 88^{-/-}$Trif ${ }^{/-}$mice (Fig. 3 E). When adoptively transferred with PTX3-sufficient NBh

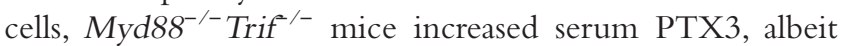
not in a statistically significant manner (Fig. 3 G). This observation suggests that TLR signals stimulate PTX3 production by activating NBh cells along with other myeloid cell types, which may include macrophages.

In agreement with the peri-MZ location of mouse NBh cells and their proximity to MZ but not FO B cells, PTX3 bound to $\mathrm{B} 220^{+} \mathrm{CD} 21^{\mathrm{hi}} \mathrm{CD} 23^{-} \mathrm{MZ}$ B cells more effectively than to $\mathrm{B} 220^{+} \mathrm{CD} 21^{10} \mathrm{CD} 23^{+}$FO B cells (Fig. 3 G). PTX3 also bound to transitional $\mathrm{B} 220^{+} \mathrm{AA} 4-1$ (or CD93 ${ }^{+}$) B cells including T1 $\mathrm{IgM}^{\mathrm{hi}} \mathrm{CD} 23^{-} \mathrm{B}$ cells, T2 $\mathrm{IgM}^{\mathrm{hi}} \mathrm{CD} 23^{+} \mathrm{B}$ cells, and T3 IgM $^{\text {lo }} \mathrm{CD}_{23}{ }^{+} \mathrm{B}$ cells (Fig. $3 \mathrm{H}$ ). These immature B cells are 
A
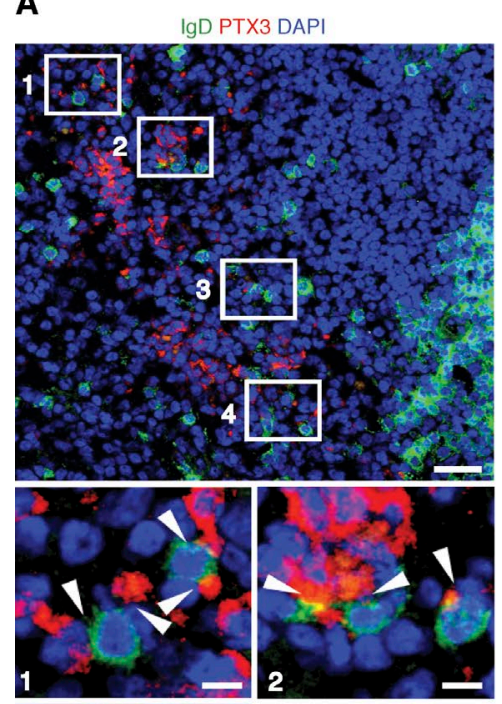

Spleen

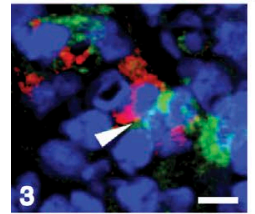

D $\quad$ Naive B cells

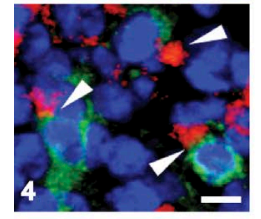

B

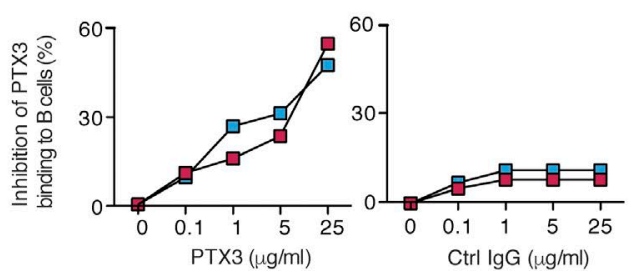

E

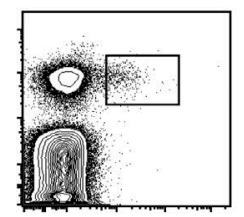

B cell-bound PTX3

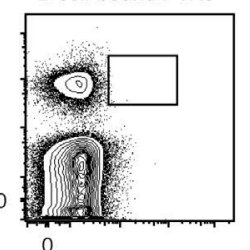

B cell-bound BSA
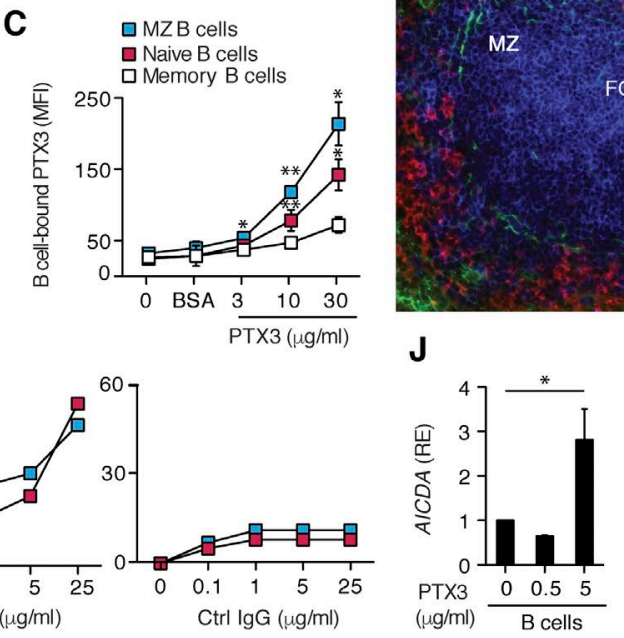

H
F

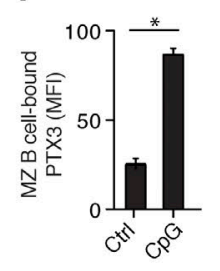

G
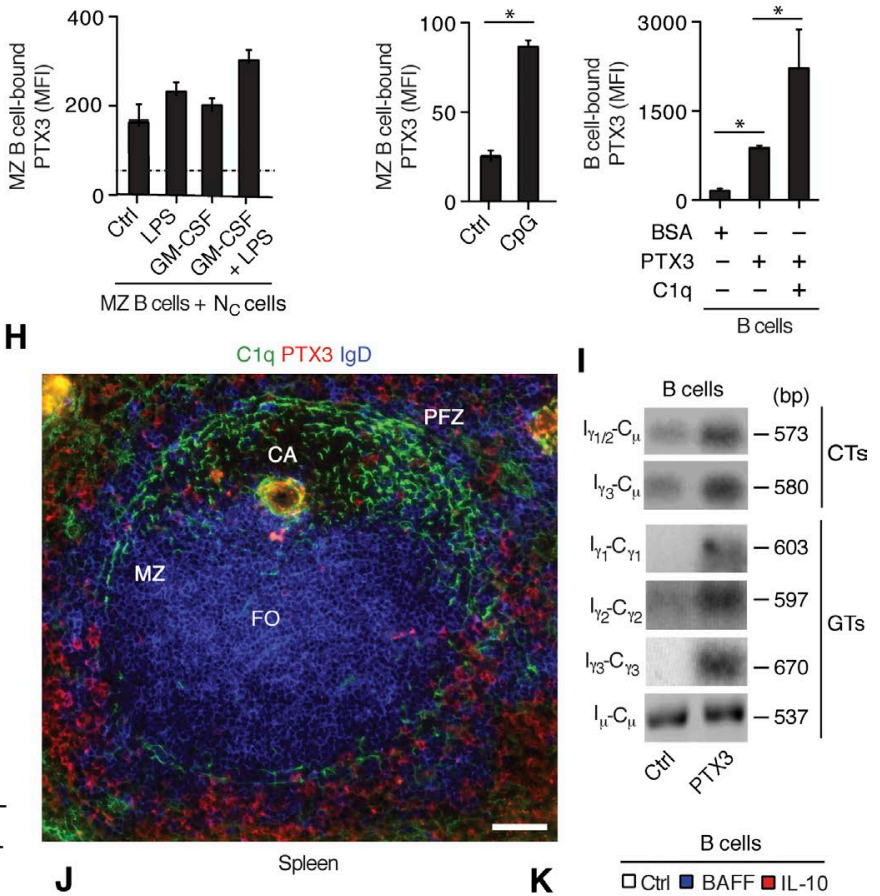

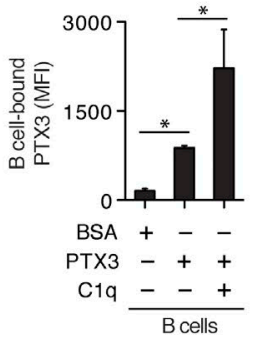

口Ctrl $\square$ BAFF $\square I L-10$

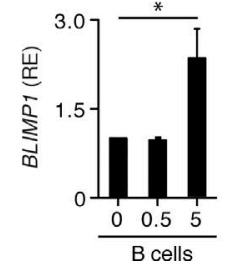

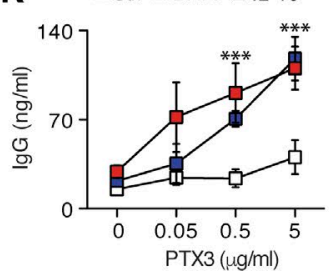

Figure 2. PTX3 from NBh cells binds to B cells and enhances CSR from IgM to $\lg$ G. (A) IFA of human splenic tissue stained for $\lg D$ (green), PTX3 (red), and DNA (blue). Boxes and arrowheads highlight lg $\mathrm{D}^{+} \mathrm{B}$ cells proximal to NBh cells, including areas of IgD-PTX3 colocalization. Bars: (top) $25 \mu \mathrm{m}$; (bottom insets) $5 \mu \mathrm{m}$. (B) Flow cytometric analysis of PTX3 and control BSA bound to human circulating CD19+ B cells. (C and D) Flow cytometric analysis of fluorochrome-labeled PTX3 bound to human circulating naive, MZ, and memory B cells before (C) and after (D) preincubation with unlabeled PTX3 or control (Ctrl) IgG. MFI, mean fluorescence intensity. (E) Flow cytometric analysis of PTX3 bound to human MZ B cells after exposure to NC cells incubated with medium alone (control), LPS, GM-CSF, or both LPS and GM-CSF for $4 \mathrm{~h}$. The dashed line indicates mean fluorescence intensity of PTX3 binding to MZ B cells cultured with medium alone. (F) Flow cytometric analysis of PTX3 bound to human splenic MZ B cells stimulated with medium alone (control) or CpG DNA for $1 \mathrm{~d}$. (G) Flow cytometric analysis of PTX3 binding to human circulating Ig $\mathrm{D}^{+} \mathrm{B}$ cells in the presence or absence of C1q. Binding of BSA is shown as the control. (H) IFA of human splenic tissue stained for C1q (green), PTX3 (red), and IgD (blue). CA, central arteriole; F0, follicle; PFZ, perifollicular zone. Bar, $100 \mu \mathrm{m}$. (I) Southern blotting of $|\mu-C \mu,| \gamma 1-C \gamma 1, \mid \gamma 2-C \gamma 2$, and l $\alpha 1-C \alpha 1$ germline transcripts (GTs) and l $\gamma$-C $\mu$ and switch l $\alpha$-C $\mu$ circle transcripts (CTs) amplified by standard reverse transcription PCR from human circulating lg $\mathrm{D}^{+} \mathrm{B}$ cells cultured with or without PTX3 for $2 \mathrm{~d}$ (germline transcripts) or $4 \mathrm{~d}$ (circle transcripts). $\mid \mu-C \mu$ was the loading control. (J) qRT-PCRs of mRNAs for AID (AICDA) and BLIMP-1 from human circulating IgD+ B cells exposed to PTX3 for $2 \mathrm{~d}$. Results are normalized to mRNA for $\beta$-actin and presented as relative expression (RE) compared with $B$ cells incubated with medium alone. (K) ELISA of total IgG from human circulating $\lg \mathrm{D}^{+} \mathrm{B}$ cells cultured for $4 \mathrm{~d}$ with medium alone (control), BAFF, or IL-10 in the presence or absence of PTX3. Data show one representative experiment of at least four with similar results $(A, B, D, H$, and $I)$ or one to two experiments with at least three samples in each experimental group ( $C, E-G$, and I-K). Error bars, SEM. ${ }^{*}, P<0.05 ;{ }^{* *}, P<0.01 ; * *, P<0.001$ (two-tailed Student's $t$ test).

usually located in the red pulp of the spleen and may participate in innate-like antibody responses to certain self and foreign antigens such as bacterial CpG DNA (Capolunghi et al.,2008).

Binding of PTX3 to MZ B cells did not involve TLR4 and FcyRs, which mediate DC responses to PTX3 (Moalli et al., 2010; Bozza et al., 2014). Indeed, MZ B cells from $\mathrm{Tlr}^{-/-}$or $\mathrm{Fcgr}^{-/-}$mice bound as much PTX3 as MZ B cells from WT mice (Fig. 3 I). This binding up-regulated AID ex- pression and IgG production in MZ B cells exposed to LPS (not depicted). Thus, mouse PTX3 is an NBh cell-derived TLR-regulated protein that binds to MZ B cells through a mechanism independent of TLR 4 and FcyRs.

PTX3 enhances homeostatic MZ B cell responses to CPS Next, flow cytometry, tissue IFA, and ELISAs were performed to evaluate humoral immunity in PTX3-deficient 
A MMP9 Ly6G IgM
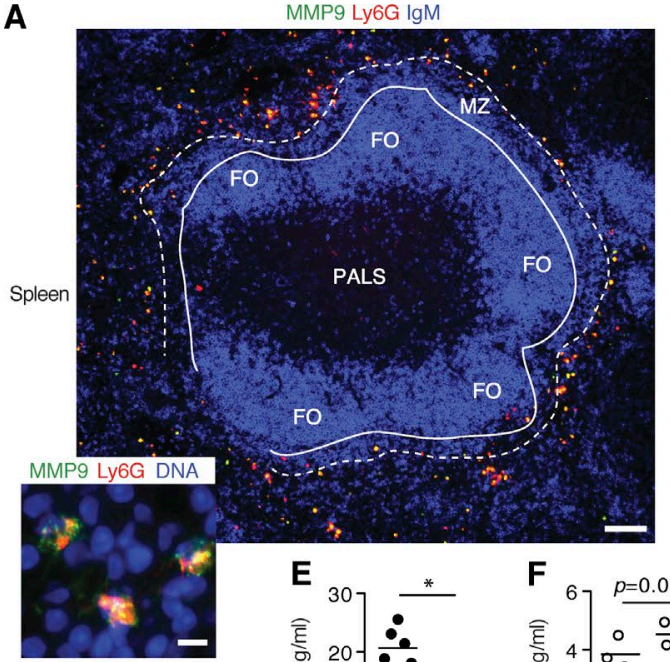

E

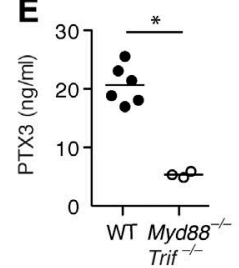

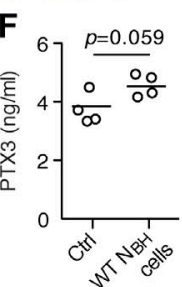

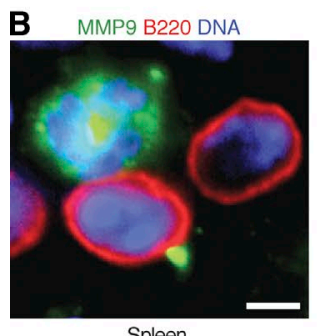

Spleen

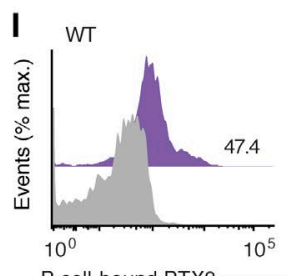

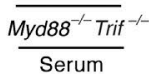

B cell-bound PTX3
C
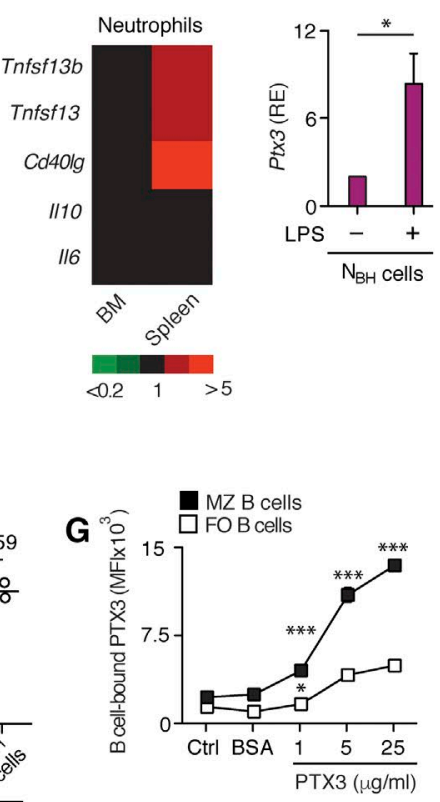

D

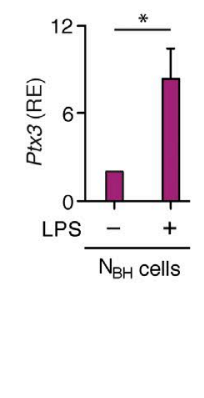

$\mathrm{Fogr}^{-1-}$

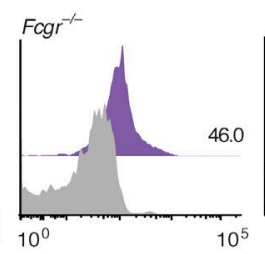

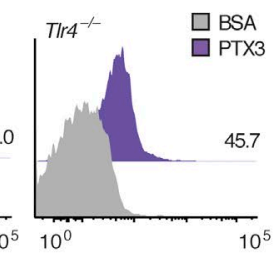

H
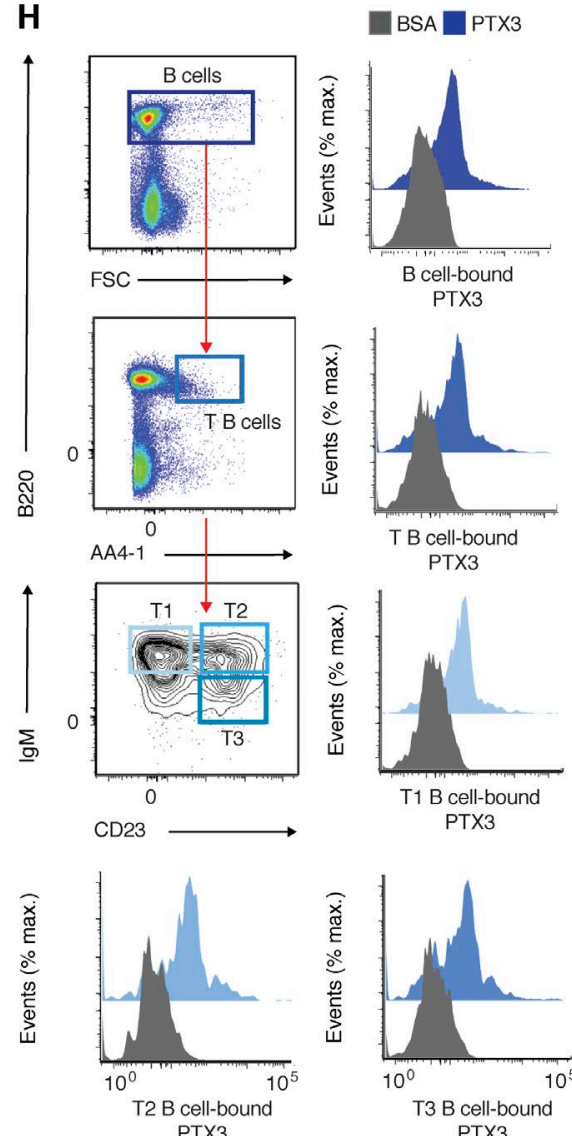

PTX3

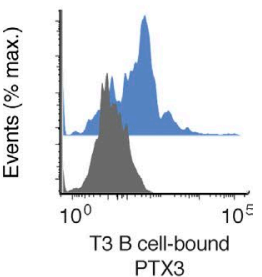

PTX3

Figure 3. PTX3 binds to MZ B cells independently of TLR4 and FcyRs. (A) IFA of mouse spleen stained for MMP9 (green), Ly6G (red), and IgM or DNA (blue). FO, follicle; PALS, periarteriolar lymphoid sheath. Bars: (top) $100 \mu \mathrm{m}$; (inset) $10 \mu \mathrm{m}$. (B) Confocal microscopy of mouse tissue stained for MMP9 (green), B220 (red), and DNA (blue). Bar, 3 um. (C) qRT-PCR of RNAs for BAFF (Tnfsf13b), APRIL (Tnfsf13), CD40L (Cd40lg), IL-10, and IL-6 in mouse neutrophils from bone marrow and spleen. Results are normalized to mRNA for HPRT and presented as relative expression compared with bone marrow neutrophils. The color code indicates high (red), mean (black), and low (green) expression. (D) qRT-PCR of mRNA for PTX3 from mouse NBh cells stimulated with LPS for $4 \mathrm{~h}$. Results are normalized to mRNA for HPRT and presented as relative expression (RE) compared with NBh cells incubated with medium alone. (E) ELISA of serum PTX3 from WT and MyD88 ${ }^{-/-}$Trif $^{-/-}$mice. (F) ELISA of serum PTX3 from MyD88 ${ }^{-/-}$Trif $^{-/-}$mice before (control [Ctrl]) and after adoptive transfer of NBh cells from WT mice. (G) Flow cytometric analysis of PTX3 or BSA binding to MZ and FO B cells from WT mice. MFl, mean fluorescence intensity. ( $\mathrm{H}$ and I) Flow cytometric analysis of PTX3-binding to splenic $B 220^{+} A A 4-1^{+}$transitional $B$ cells ( $B$ cell), including $B 220^{+} A A 4-1^{+} C D 23^{-} I g M^{\text {hi }} T 1 B^{B}$ cells,

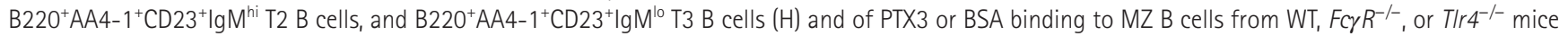
(I). Data show one representative experiment of at least four with similar results $(A, B, H$, and $I)$ or one to two experiments with at least three samples in each experimental group (C-G). Error bars, SEM. ${ }^{*}, \mathrm{P}<0.05{ }^{* * *}, \mathrm{P}<0.001$ (two-tailed Student's $t$ test).

mice $\left(P t \times 3^{-/-}\right)$. Spleens from $P t \times 3^{-/-}$mice showed conserved total B cells, FO B cells, and MZ B cells as well as $\mathrm{B} 220^{+} \mathrm{CD} 21^{-} \mathrm{CD} 23^{-} \mathrm{CD} 43^{+} \mathrm{B}-1$ cells, including $\mathrm{CD} 5^{+} \mathrm{B}-1 \mathrm{a}$ and $\mathrm{CD}^{-} \mathrm{B}-1 \mathrm{~b}$ subsets (Fig. 4 A). Despite having normal splenic B220 ${ }^{-} \mathrm{CD} 138^{+} \mathrm{PBs} / \mathrm{PCs}$ and normal total serum IgM, preimmune $P t \times 3^{-/}$mice had reduced serum IgM to TI antigens such as CPS, lipoteichoic acid, and phosphorylcholine (Fig. 4 B). This humoral deficiency correlated with reduced MZ B cell expression of BLIMP-1 but not with alterations of Ly $6 \mathrm{G}^{+} \mathrm{MMP}^{+} \mathrm{NBh}$ cells and MZ-associated MOMA-1 ${ }^{+}$ metallophilic macrophages (Fig. 4, C-E).
We then took advantage of bronchoalveolar lavage (BAL) fluids from sarcoidosis patients harboring distinct haplotypic variants of the gene encoding PTX3 (Cunha et al., 2014). Although $h 1 / h 1$ and $h 1 / h 2$ variants do not affect PTX $3, \mathrm{~h} 2 / \mathrm{h} 2$ variants impair neutrophil production of PTX3 (Cunha et al., 2014). Compared with h1/h1 and h1/h2 patients with PTX3-sufficient neutrophils, h2/h2 patients with PTX3-deficient neutrophils showed decreased CPS-reactive IgG but normal total IgG in BAL fluids (Fig. 4 F). Thus, PTX3 enhances homeostatic antibody responses to TI antigens in both mice and humans. 

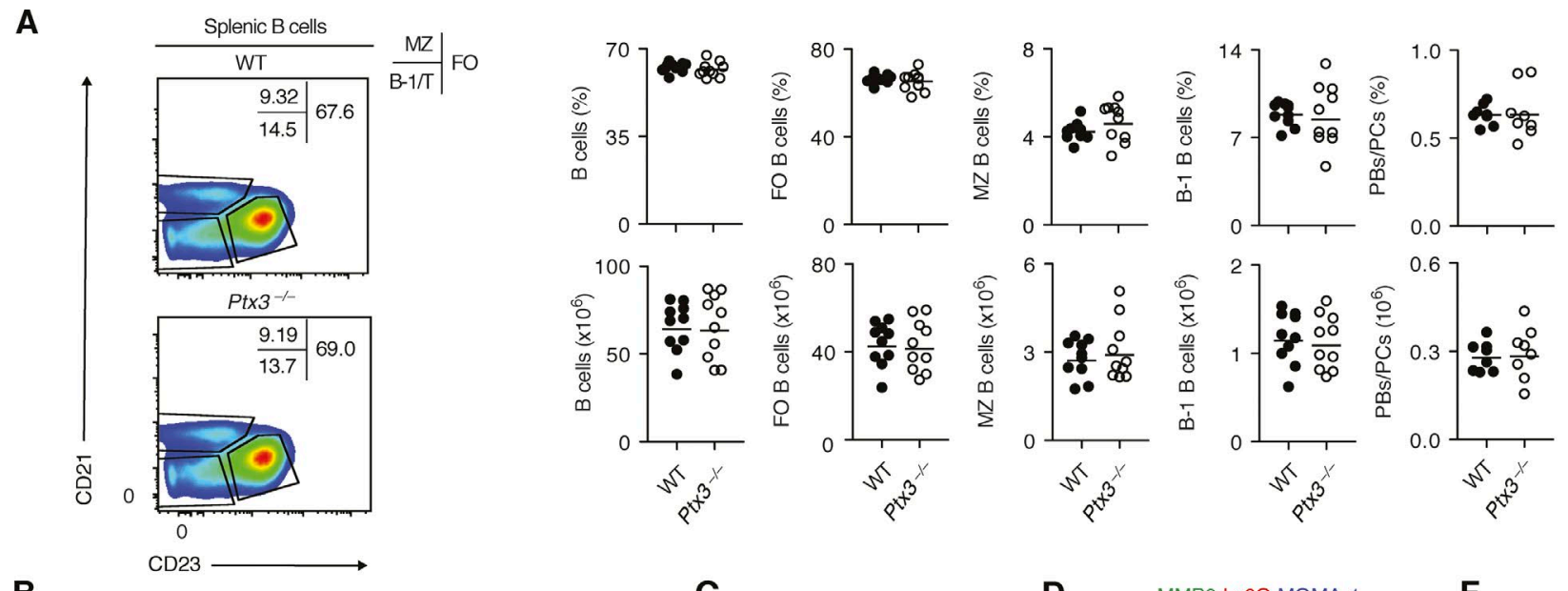

B
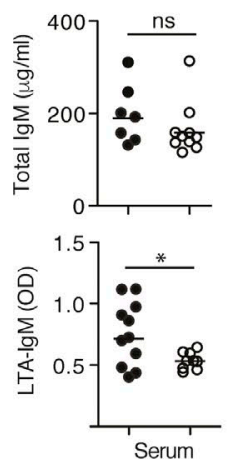
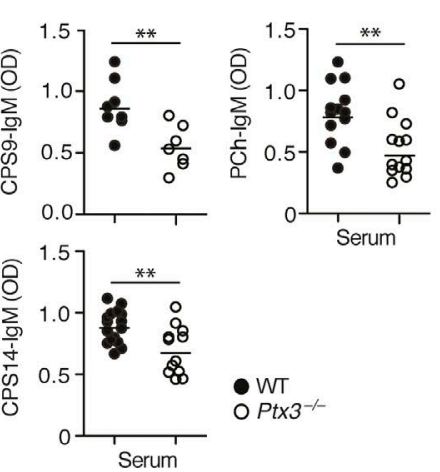

C
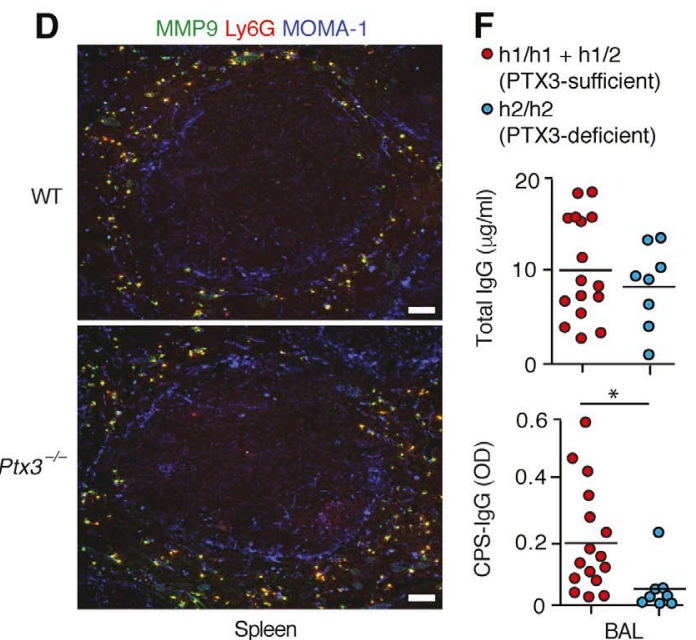

Figure 4. PTX3 enhances homeostatic IgM and IgG responses to CPS. (A) Flow cytometric analysis of frequency and absolute number of total B220 ${ }^{+}$

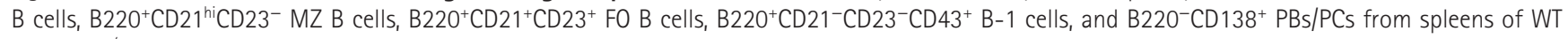

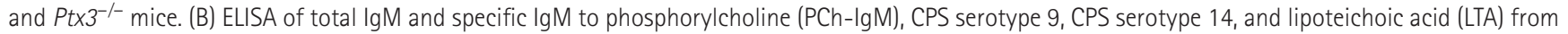
serum of WT and $P t \times 3^{-/-}$mice. OD was at $450 \mathrm{~nm}$. Data show serum total and antigen-specific lgs from 7-10 mice in each experimental group. (C) qRTPCR of mRNA for BLIMP-1 (Prdm 1) in MZ B cells from WT and Ptx $3^{-/-}$mice. Results are normalized to mRNA for HPRT and presented as relative expression (RE) compared with MZ B cells from WT mice. (D) IFA of spleens from WT and Ptx $3^{-/-}$mice stained for MMP9 (green), Ly6G (red), and MOMA-1 (blue). Bars, $100 \mu \mathrm{m}$. (E) Flow cytometric quantification of NBh cells from spleens of WT and Ptx $3^{-/-}$mice. (F) ELISA of total and CPS-reactive IgG in BAL fluids from PTX3-sufficient $h 1 / h 1$ and $h 1 / h 2$ patients and PTX3-deficient $h 2 / h 2$ patients. Data show one representative experiment of at least two with similar results $(A$ and $D)$, summarize one to two experiments with at least eight mice in each experimental group ( $A$ and $C-E)$, or show one experiment with samples from at least eight donors in each experimental group (F). Error bars, SEM. ${ }^{*}, \mathrm{P}<0.05 ;{ }^{*}{ }^{*}, \mathrm{P}<0.01$ (two-tailed Student's $t$ test).

PTX3 enhances MZ B cell responses to encapsulated bacteria Next, we determined the role of PTX3 in mouse postimmune IgM and $\operatorname{IgG}$ responses to Streptococcus pneumoniae (SP), a CPS-expressing encapsulated microbe that elicits robust TI antibody production (Guinamard et al., 2000). As indicated by tissue IFA, ELISA, and flow cytometry, NBh cells from WT mice extensively interacted with $\mathrm{B} 220^{+} \mathrm{B}$ cells from splenic $\mathrm{MZ}$ but not follicular areas and enhanced PTX3 release as early as $3 \mathrm{~d}$ after i.v. infection with SP (Fig. 5, A-C; and not depicted).

Compared with WT mice, infected $P t \times 3^{-1-}$ mice showed a reduction of splenic NBh cells as well as MZ, B-1a, and $\mathrm{B}-1 \mathrm{~b} \mathrm{~B}$ cells, including those expressing nuclear Ki-67 as a result of ongoing proliferation (Fig. 5, D-F). Infected $\mathrm{Pt}_{\mathrm{S}} \mathrm{3}^{-/-}$mice also showed a reduction of splenic total $\mathrm{B}$ cells, FO B cells, and PBs/PCs, whereas splenic proliferating Ki$67^{+}$FO B cells did not decrease (not depicted). As shown by qRT-PCR and flow cytometry, these changes correlated with impaired MZ B cell expression of AID and germline I $\gamma 2 b-$ $\mathrm{C} \gamma 2 \mathrm{~b}$ and $\mathrm{I} \gamma 2 \mathrm{c}-\mathrm{C} \gamma 2 \mathrm{c}$ transcripts and decreased class-switched B cells expressing IgG2b, IgG2c, or IgG3 (Fig. 5, G and H). Besides polysaccharides, SP expresses proteins that may be recognized by PTX3 to initiate TD antibody responses via DCs (Colino et al., 2002; Bozza et al., 2014; Bottazzi et al., 2015). Accordingly, infected $P t \times 3^{-/-}$mice showed fewer splenic $\mathrm{CD} 3{ }^{+} \mathrm{CD} 4^{+} \mathrm{CXCR} 5{ }^{\text {hi }} \mathrm{PD}-1^{\text {hi }} \mathrm{T}$ follicular helper cells 
A
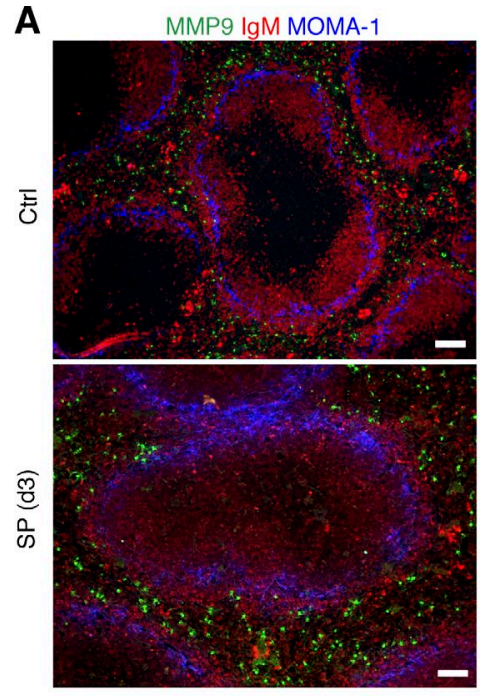

E
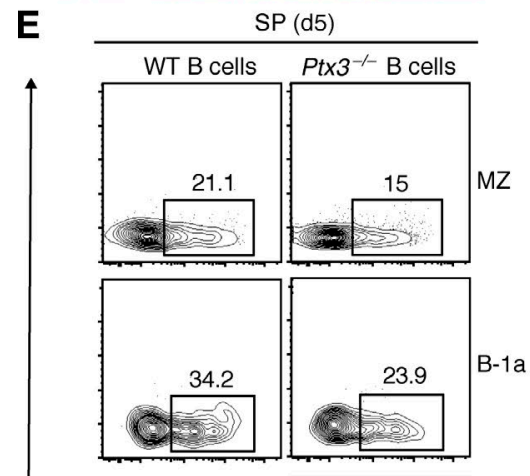

.

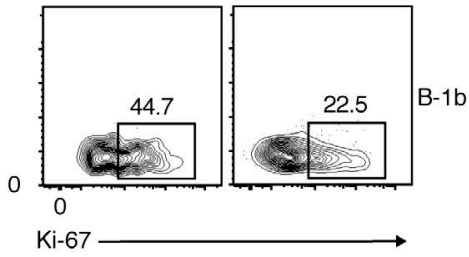

B

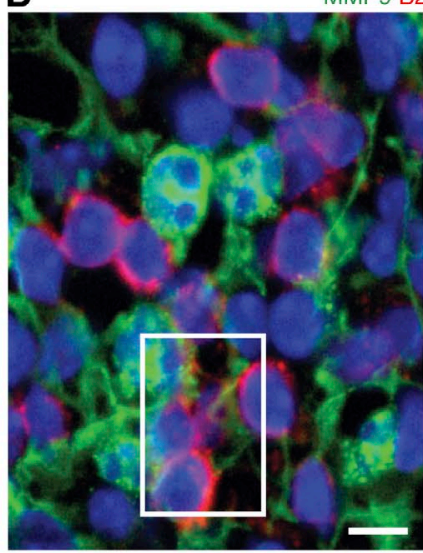

SP (d3)

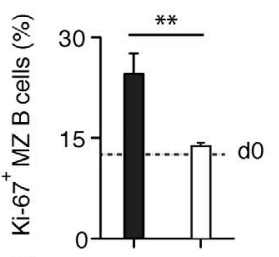

$\widehat{\circ} 50$
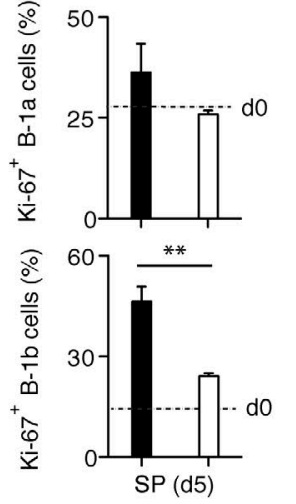

F
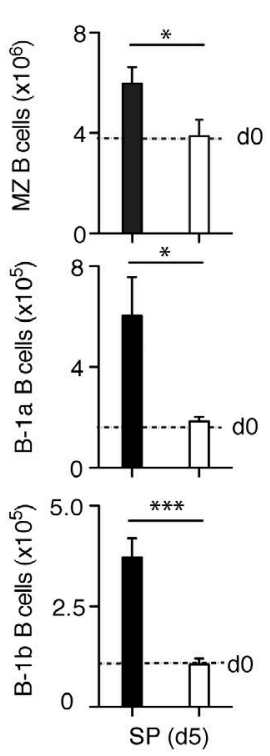

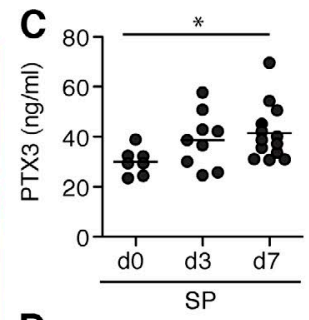

D

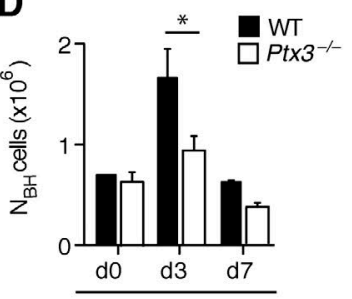

G
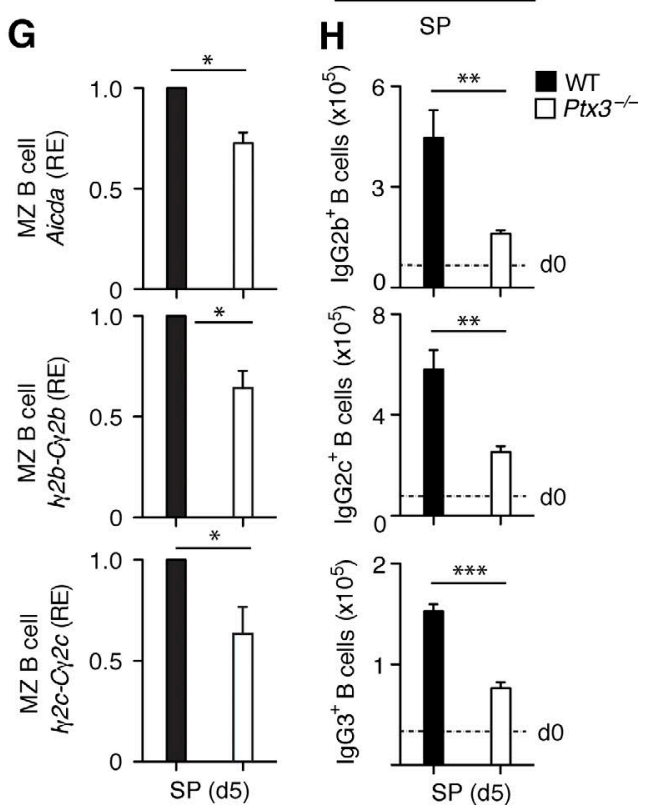

Figure 5. PTX3 enhances MZ B cell proliferation and CSR from IgM to $\lg$ G in response to encapsulated bacteria. (A) IFA of spleens from WT mice stained for MMP9 (green), IgM (red), and MOMA-1 (blue) before (control [Ctrl]) and after (d3) i.v. injection of live SP. Bars, $100 \mu$ m. (B) Confocal microscopy of mouse splenic tissue stained for MMP9 (green), B220 (red), and DNA (blue) after i.v. injection (d3) of live SP. The right image corresponds to the magnified boxed tissue area from the left image, which depicts B cell-interacting NBh cells. Arrowheads point to B220 captured by an MMP9+ NBh cell. Bars: (left) $10 \mu \mathrm{m}$; (right) $3 \mu \mathrm{m}$. (C) ELISA of serum PTX3 from WT mice after i.v. injection of live SP. (D) Flow cytometric quantification of NBh cells from WT and

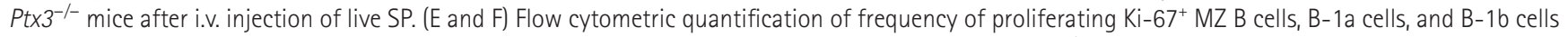
(E) and absolute number of total MZ B cells, B-1a cells, and B-1b cells (F) from spleens of WT and Ptx $3^{-/-}$mice after i.v. injection (d5) of live SP. Dashed lines show the mean frequency or absolute number in nonimmunized WT mice. Similar values were obtained in nonimmunized $P t \times 3^{-/-}$mice. FSC, forward side scatter. (G) qRT-PCR of mRNAs for AID (Aicda), l $\gamma 2 b-C \gamma 2 b$, and $1 \gamma 2 c-C \gamma 2 c$ transcripts in MZ B cells from WT and Ptx $3^{-/-}$mice after i.v. injection (d5) of live SP. Results are normalized to mRNA for HPRT and presented as relative expression (RE) compared with MZ B cells from WT mice. (H) Absolute numbers of class-switched B cells expressing lgG2b, IgG2c, or lgG3 from spleens of WT and Ptx $3^{-/-}$mice after i.v. injection (d5) of live SP. Dashed lines show the mean frequency or absolute number in nonimmunized WT mice. Similar values were obtained in nonimmunized $P t \times 3^{-/-}$mice. Data show one representative experiment of at least three with similar results $(\mathrm{A}$ and $\mathrm{B})$ or summarize two experiments with at least three mice in each experimental group $(\mathrm{C}-\mathrm{H})$. Error bars, SEM. ${ }^{*}, \mathrm{P}<0.05 ;{ }^{* *}, \mathrm{P}<0.01 ;{ }^{* * *}, \mathrm{P}<0.001$ (two-tailed Student's $t$ test).

(not depicted), a T cell subset required for the induction of TD antibody responses in the germinal center (GC; Victora and Nussenzweig, 2012).

We next characterized the $\mathrm{PB} / \mathrm{PC}$ compartment of SP-immunized WT and Ptx $3^{-/-}$mice. ELISA, ELISPOT, and flow cytometry showed that, compared with WT mice, Ptx $3^{-/-}$ mice had decreased serum levels of SP-specific IgG2b, IgG2c, IgG3, and IgM and decreased SP-specific antibody-secreting cells in the spleen, including PBs/PCs expressing transcripts for AID as well as PBs/PCs expressing surface and/or intra- 
A
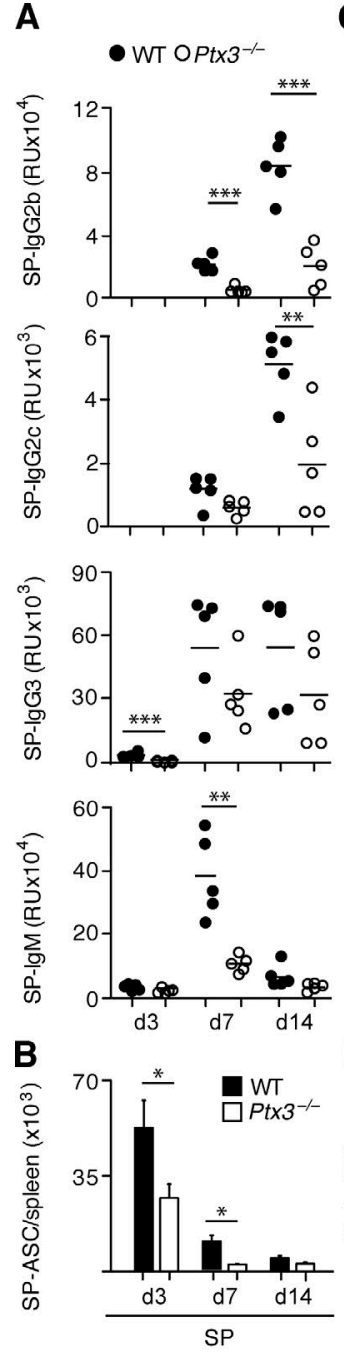

C
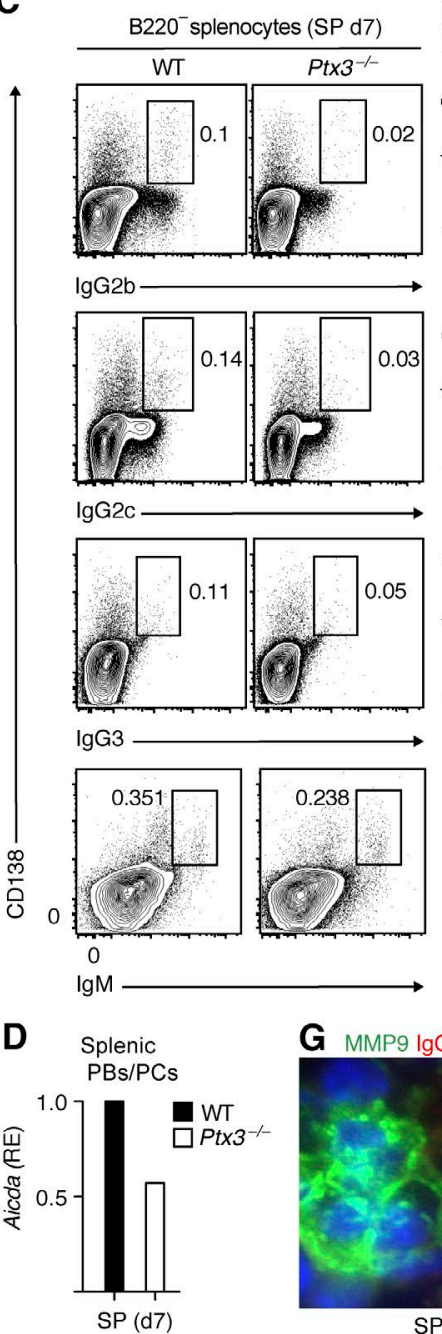
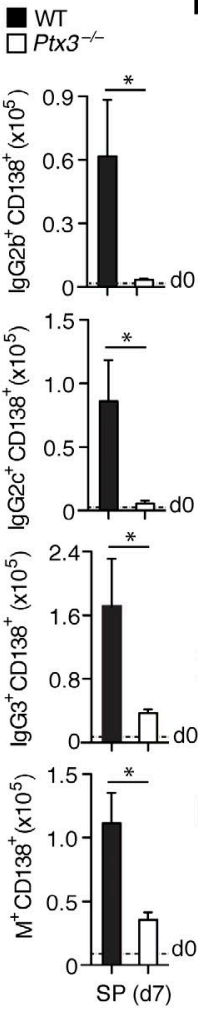

G MMP9 IgG2c DNA

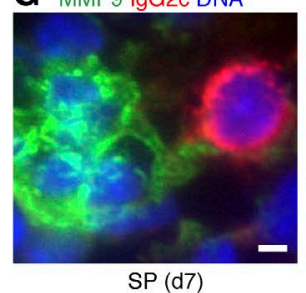

$\mathbf{E}$

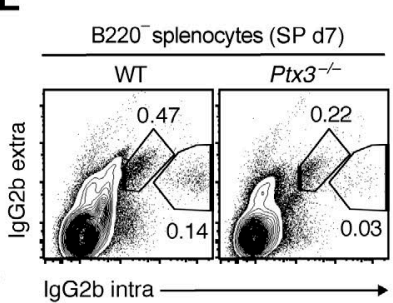

WT
$\square$ Ptx3
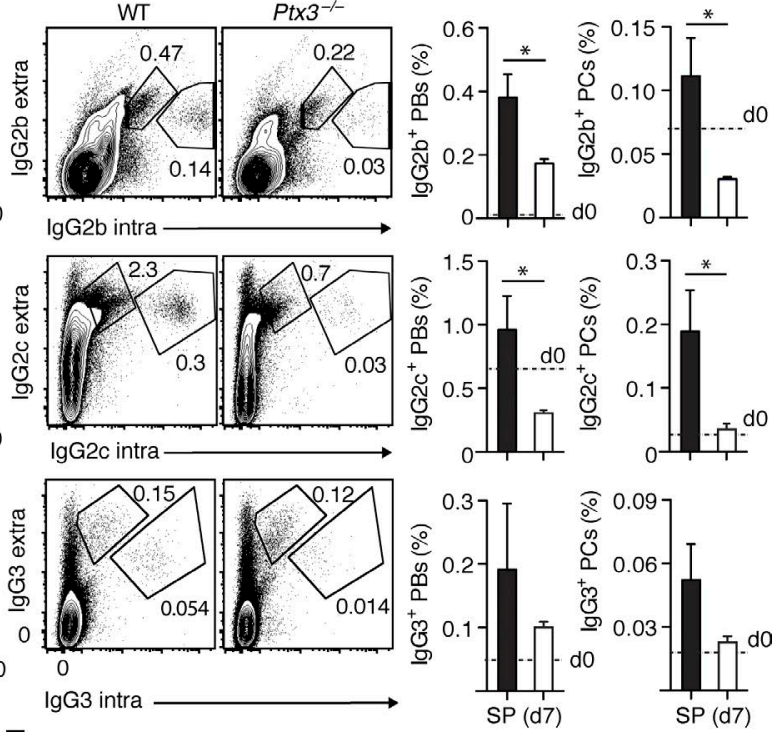

$\mathbf{F}$
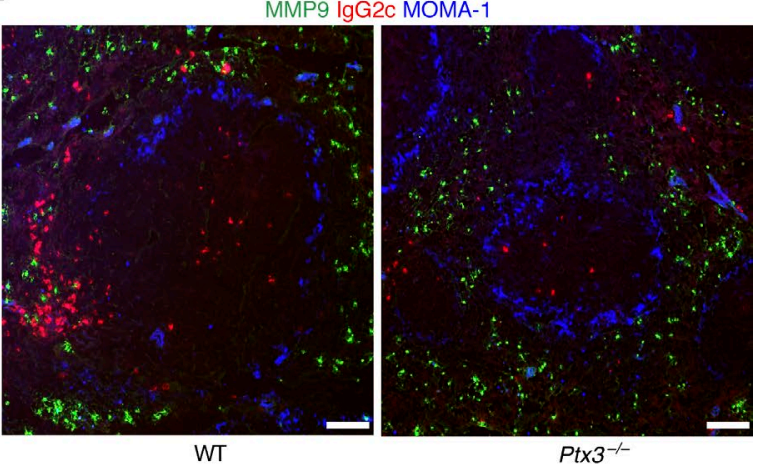

$\mathrm{SP}(\mathrm{d} 7)$

Figure 6. PTX3 enhances PB and PC expansion as well as IgG production in response to encapsulated bacteria. (A and B) ELISA of serum SP-reactive $\lg G 2 b, \lg G 2 c$, IgG3, and $\lg M(A)$ and ELISPOT of splenic SP-reactive antibody-secreting cells (ASCs; B) from WT and Ptx $3^{-/-}$mice after i.v. injection (d7) of live SP. RU, relative units. (C) Flow cytometric quantification of frequency (left cytograms) and absolute number (right graphs) of B220-CD138 ${ }^{+}$PBs/PCs expressing $\lg \mathrm{M}$ or class-switched $\lg \mathrm{G} 2 \mathrm{~b}, \lg \mathrm{g} 2 \mathrm{c}$, and $\lg \mathrm{G} 3$ from WT and Ptx $3^{-/}$mice after i.v. injection (d7) of live SP. Dashed lines show the mean frequency or absolute number in nonimmunized WT mice. Similar values were obtained in nonimmunized Ptx $3^{-/-}$mice. (D) qRT-PCR of mRNA for AID (Aicda) in splenic B220-CD $138^{+}$PBs/PCs from WT and Ptx $3^{-/-}$mice after i.v. injection (d7) of live SP. Results are normalized to mRNA for HPRT and are presented as relative expression (RE) compared with PBs/PCs from WT mice. (E) Flow cytometric quantification of frequency of splenic B220- PBs expressing extracellular (extra) but not intracellular (intra) IgG2b, IgG2c, or IgG3 (left) as well as splenic B220- PCs expressing both extracellular and intracellular IgG2b, IgG2c, or IgG3 (right) from WT and Ptx $3^{-/-}$mice after i.v. injection (d7) of live SP. Dashed lines show the mean frequency or absolute number in nonimmunized WT mice. Similar values were obtained in nonimmunized Ptx $3^{-/-}$mice. (F) IFA of spleens stained for MMPg (green), IgG2c (red), and MOMA-1 (blue) from WT and Ptx $3^{-/}$mice after i.v. injection (d7) of live SP. Bars, $50 \mu \mathrm{m}$. (G) IFA of splenic tissue from SP-infected WT mice stained for MMP9 (green), IgG2c (red), and DNA (blue) from WT mice after i.v. injection (d7) of live SP. Bar, $3 \mu \mathrm{m}$. Data summarize at least two experiments with at least three mice in each experimental group ( $A-C$ and $E$ ) or one representative experiment of at least three with similar results $(D, F$, and $G)$. Error bars, $S E M .{ }^{*}, P<0.05 ;{ }^{* *}, P<0.01 ;^{* * *}, P<0.001$ (two-tailed Student's $t$ test).

cellular IgG2b, IgG2c, IgG3, or IgM (Fig. 6, A-E). Tissue IFA confirmed the reduction of splenic B cells accumulating cytoplasmic IgG2c in $P t \times 3^{-/-}$mice as compared with WT mice, which clearly showed splenic NBh cells closely interacting with IgG2c-expressing B cells (Fig. 6, F and G). Thus, PTX3 stimulates innate-like B cell subsets, including MZ B cells, to undergo expansion and IgG class switching as well as PB and $\mathrm{PC}$ differentiation in response to encapsulated bacteria.

\section{PTX3 enhances TI and TD antibody-inducing pathways}

Besides CPS, encapsulated bacteria express proteins and thus can instigate antibody production through both TI and TD 

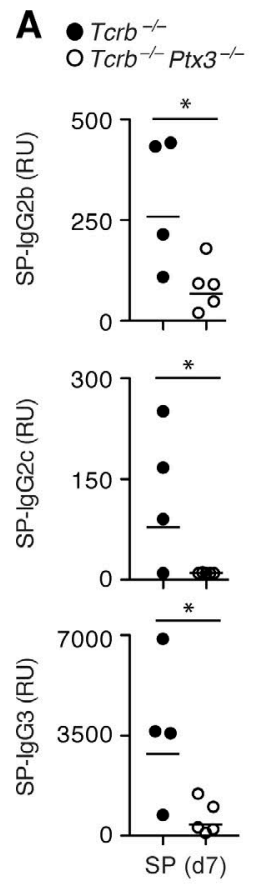

B
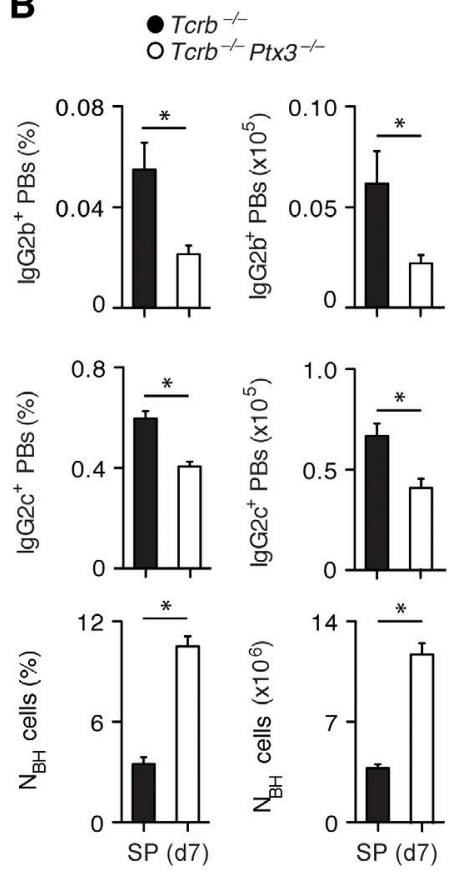
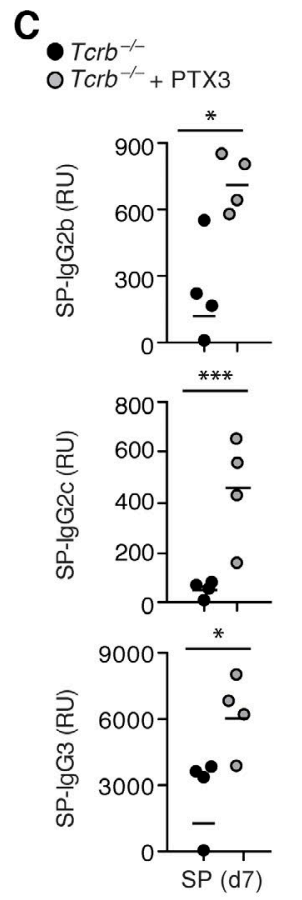

D
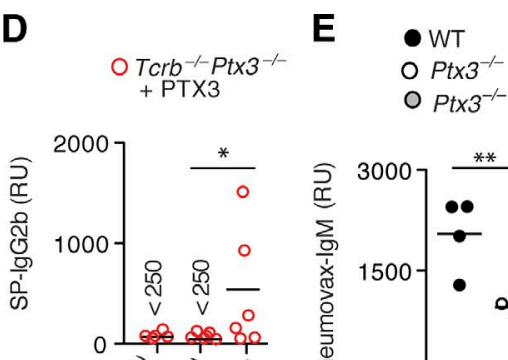

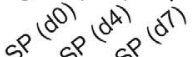
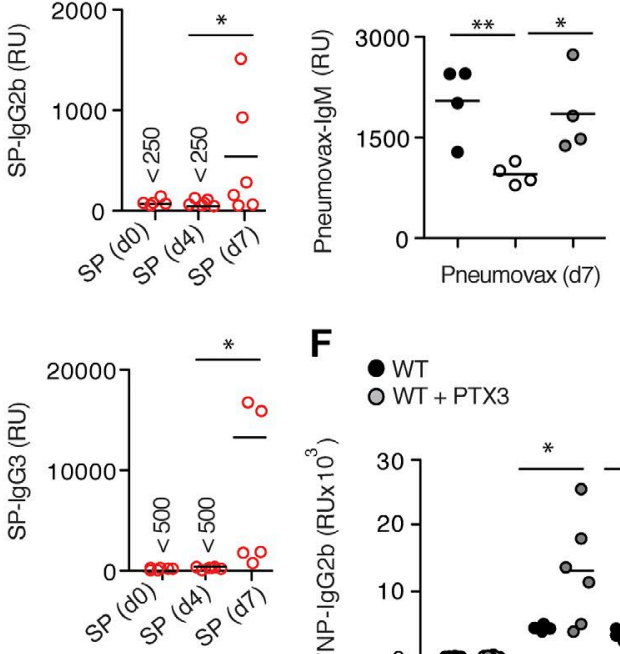

$\mathbf{F} \bullet W T$

OWT + PTX3

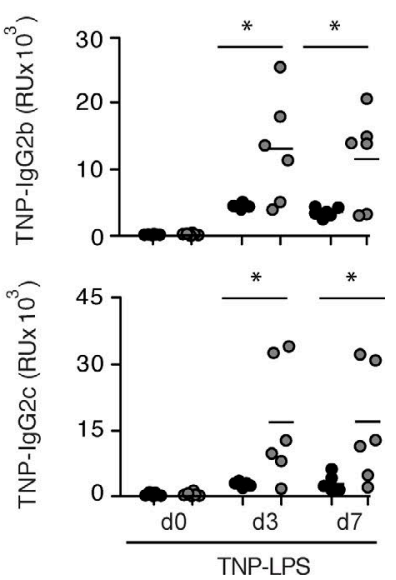

Figure 7. PTX3 can enhance IgG responses to microbial carbohydrates by activating a TI pathway. (A) ELISA of serum SP-reactive IgG2b, IgG2C, and IgG3 from $\mathrm{Trb}^{-/-}$and $\mathrm{Tcrb}^{-/-} \mathrm{Ptx} 3^{-/-}$mice after i.v. injection (d7) of live SP. RU, relative units. (B) Flow cytometric analysis of frequency (left) and absolute number (right) of splenic class-switched PBs expressing IgG2b or IgG2c and splenic NBh cells from Tcrb ${ }^{-/-}$and $T c r b^{-/-} P t \times 3^{-/-}$mice after i.v. injection (d7) of live SP. (C) ELISA of serum SP-reactive IgG2b, IgG2c, and IgG3 from $\mathrm{Tcrb}^{-/-}$mice after i.v. injection (d7) of live SP with or without exogenous PTX3. (D)

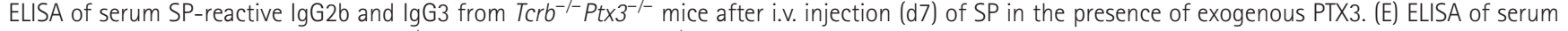
Pneumovax-specific lgM from WT, Ptx $3^{-/}$, and PTX3-treated $P t \times 3^{-/-}$mice at day 7 after i.v. immunization with Pneumovax. (F) ELISA of serum TNP-reactive $\lg \mathrm{G} 2 \mathrm{~b}$ and $\lg \mathrm{G} 2 \mathrm{c}$ from WT mice after i.v. injection (d7) of TNP-LPS with or without exogenous PTX3. Data summarize at least two experiments with at least three mice in each experimental group. Error bars, SEM. ${ }^{*}, P<0.05 ;{ }^{*}, P<0.01 ;{ }^{* *}, P<0.001$ (two-tailed Student's $t$ test).

pathways (Guinamard et al., 2000; Colino et al., 2002). Accordingly, T cell-deficient $\mathrm{Tcrb}^{-/-}$mice mounted IgG2b, $\operatorname{IgG} 2 \mathrm{c}$, and IgG3 responses after SP infection, but these responses were weaker than those induced by $\mathrm{T}$ cell-sufficient WT mice (Fig. $7 \mathrm{~A}$ and, for comparison, Fig. $6 \mathrm{~A}$ ). The involvement of PTX3 in TI responses was further determined by crossing $\mathrm{Ptx}_{\mathrm{X} 3^{-/-}}$with $\mathrm{Tcrb}^{-/-}$mice. Compared with SP-immunized $\mathrm{Tcrb}^{-/-}$mice, SP-immunized $\mathrm{Tcrb}^{-/-} \mathrm{Ptx} \mathrm{3}^{-/-}$ mice produced less SP-specific IgG2b, IgG2c, and IgG3, and their spleen had fewer splenic IgG class-switched PBs, despite containing more NBh cells (Fig. 7, A and B). Conversely, administration of PTX3 enhanced specific IgG2b, IgG2c, and IgG3 responses in SP-immunized $T c r b^{-/-}$or $\mathrm{Tcrb}^{-/-} \mathrm{Ptx}_{\mathrm{X}} \mathrm{I}^{-/-}$ mice (Fig. 7, C and D).

Subsequent experiments ascertained the role of PTX3 in antibody responses to different soluble TI antigens. Compared with WT mice, $P t \times 3^{-/-}$mice produced less IgM after i.v. immunization with Pneumovax (Fig. 7 E), a human vaccine that contains a mix of CPS from multiple SP serotypes. Of note, administration of exogenous PTX3 restored IgM responses to Pneumovax in $P t \times 3^{-/-}$mice. Similarly, treatment of WT mice with exogenous PTX3 increased $\operatorname{IgG} 2 \mathrm{~b}$ and IgG2c responses to 2,4,6 TNP-LPS (Fig. 7 F), a TI antigen expressed by Gram-negative bacteria.

Finally, we verified whether PTX3 enhanced antibody responses to soluble or particulate TD antigens, including PTX3-insensitive OVA and PTX3-sensitive influenza virus (Reading et al., 2008; Bottazzi et al., 2015). Compared with WT mice, Ptx $3^{-/}$mice showed conserved antigen-specific $\operatorname{IgG} 2 b$ and $\operatorname{Ig} G 2 c$ responses after i.p. immunization with 4-hydroxy-3-nitrophenylacetyl (NP)-conjugated OVA (Fig. 8 A). i.n. infection with PR 8 influenza A virus triggered an early increase of NBh cells (Fig. 8 B), suggesting a potential involvement of PTX3 in antiviral responses. Indeed, 
A
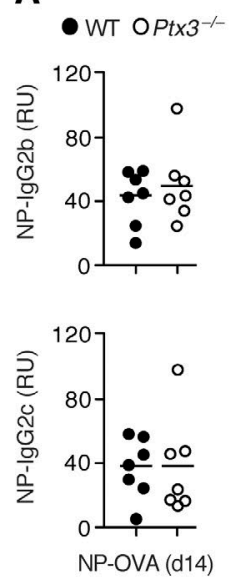

B

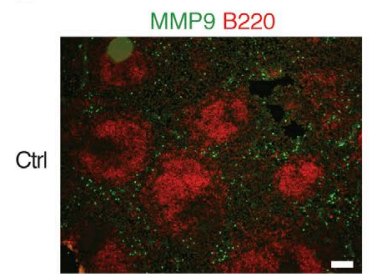

d1
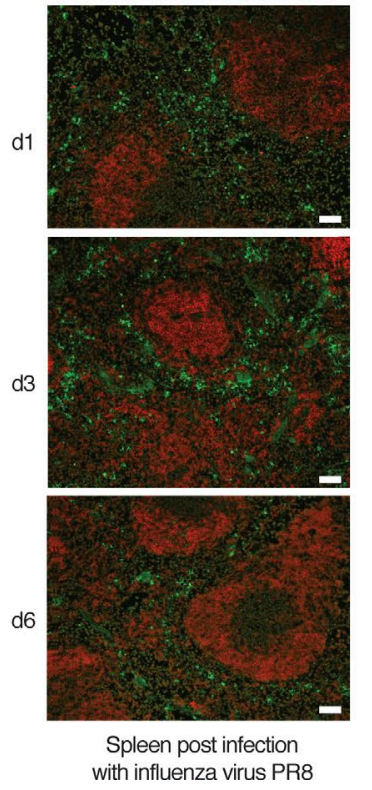

C

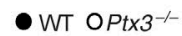
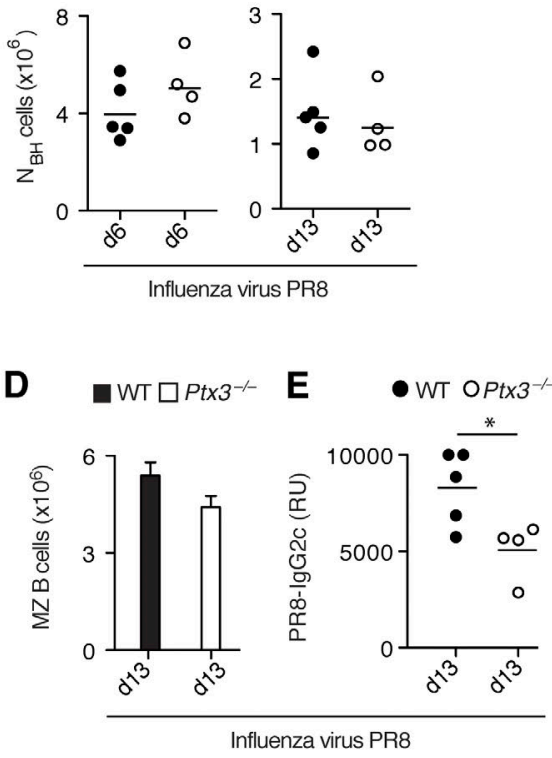

Figure 8. PTX3 deficiency mitigates IgG responses to particulate but not soluble TD antigens. (A) ELISA of serum NP-specific IgG2b and $\operatorname{lgG} 2 \mathrm{c}$ from WT and $P t \times 3^{-/-}$mice at day 14 after i.p. immunization with NP-OVA and alum. $R U$, relative units. (B) IFA of spleens stained for MMP9 (green) and B220 (red) from WT mice i.n. infected with PR8 influenza virus. Ctrl, control. Bars, $50 \mu \mathrm{m}$. (C and D) Flow cytometric analysis of absolute numbers of NBh cells $(C)$ and $M Z B$ cells (D) from WT and Ptx $3^{-/-}$mice i.n. infected with PR8 influenza virus. (E) Serum PR8-specific IgG2c in WT and Ptx $3^{-/-}$mice i.n. infected with PR8 influenza virus. Data summarize one to two experiments with at least three mice in each experimental group ( $A$ and $C-E$ ) or show one representative experiment of three with similar results (A). Error bars, SEM. ${ }^{*}, \mathrm{P}<0.05$ (two-tailed Student's $t$ test).
$\mathrm{Ptx}^{-/-}$mice produced less PR8-specific IgG2c antibodies than WT mice, albeit showing comparable numbers of splenic $\mathrm{NBh}$ and MZ B cells (Fig. 8, C-E). Thus, mouse PTX3 may enhance IgM and IgG responses by activating $\mathrm{MZ} B$ cells and possibly other B cell subsets through signals emanating from both TI and TD pathways.

PTX3-expressing neutrophils exert MZ B cell helper activity Given that multiple cell types release PTX3 (Bottazzi et al., 2010), we determined the specific contribution of NBh cells to PTX3-induced antibody responses. qRT-PCR and ELISA demonstrated that, in the presence of LPS, highly purified $\mathrm{NBh}$ cells from Ptx $3^{-/-}$mice induced less MZ B cell expression of germline $\mathrm{I} \gamma 2 \mathrm{~b}-\mathrm{C} \gamma 2 \mathrm{~b}$ transcripts, AID transcripts, and IgG2b proteins than did highly purified NBh cells from WT mice (Fig. 9 A and Fig. S2 A). However, addition of exogenous PTX3 restored the MZ B cell helper activity of NBh cells from $P t \times 3^{-1-}$ mice (Fig. 9 A).

Considering that IgG CSR requires NF- $\mathrm{KB}$ (Honjo et al., 2002), we used a qRT-PCR-based gene array to test whether MZ B cells exposed to PTX3 from NBh cells activate an NF- $\mathrm{BB}-$ dependent gene program. Compared with $\mathrm{NBh}$ cells from WT mice, NBh cells from $\mathrm{Ptx}^{-/-}$mice induced less MZ B cell expression of NF- $\mathrm{KB}-$ dependent gene products implicated in survival, apoptosis, activation, and proliferation, including transcripts for IL-2 receptor $\alpha$ chain
(CD25), C3, BIRC2, GADD45B, XIAP (X-linked inhibitor of apoptosis protein), FAS, and MYC (Fig. 9 B). Of note, complementation of PTX3-deficient NBh cells with exogenous PTX3 restored MZ B cell induction of many of these $\mathrm{NF}-\kappa \mathrm{B}-$ dependent gene products (Fig. $9 \mathrm{~B}$ ).

We next evaluated the contribution of NBh cell-derived PTX3 to IgG responses against TI antigens. Ptx $3^{-/-}$mice i.v. immunized with SP after adoptive transfer of PTX3-deficient $\mathrm{NBh}$ cells showed attenuated SP-specific IgG2b, IgG2c, and IgG3 responses and fewer MZ but not FO B cells as compared with immunized $P t \times 3^{-/-}$mice adoptively transferred with PTX3-sufficient NBh cells (Fig. 9, C-E). This result was not caused by differences in splenic colonization by transferred NBh cells (Fig. S2 B).

To further confirm the involvement of NBh cells in TI IgG responses, mice were injected with the neutrophil-depleting $1 \mathrm{~A} 8 \mathrm{mAb}$ before and during i.v. immunization with TNP-Ficoll, a polysaccharide mimicking CPS from SP. Similar to WT mice exposed to SP,TNP-Ficoll-immunized mice showed an accumulation of NBh cells nearby MZ B cells capturing TNP-Ficoll (Fig. 10 A). Compared with control neutrophil-sufficient mice, neutrophil-deficient mice had fewer splenic PBs and PCs expressing IgG2b, IgG2c, or IgG3 as well as decreased serum levels of TNP-specific but not total IgG2b, IgG2c, IgG3, and IgM after immunization (Fig. 10, B-E; and not depicted). When initiated $3 \mathrm{~d}$ after 
A

WT $\mathrm{N}_{\mathrm{BH}}$ cells $\square$ Ptx $3^{-/-} \mathrm{N}_{\mathrm{BH}}$ cells
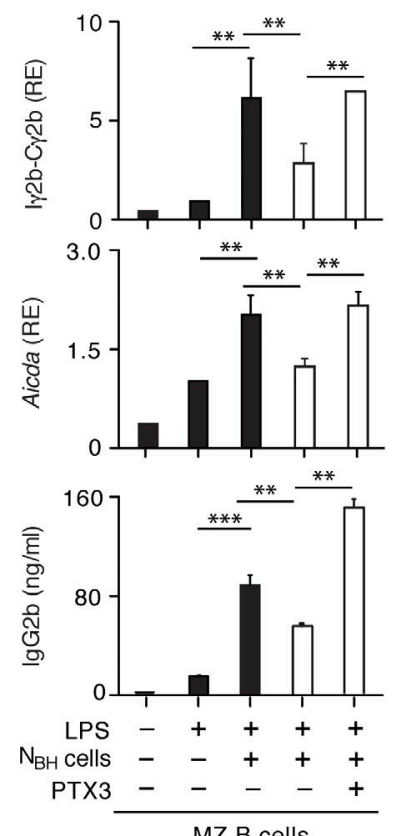

B

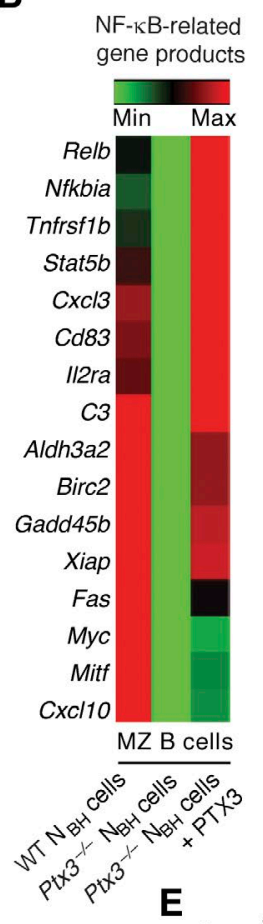

C • wT

O Ptx $3^{-1-}$ neutrophils $\rightarrow P t \times 3^{-1-}$

O WT neutrophils $\rightarrow P_{t \times 3^{--}}$
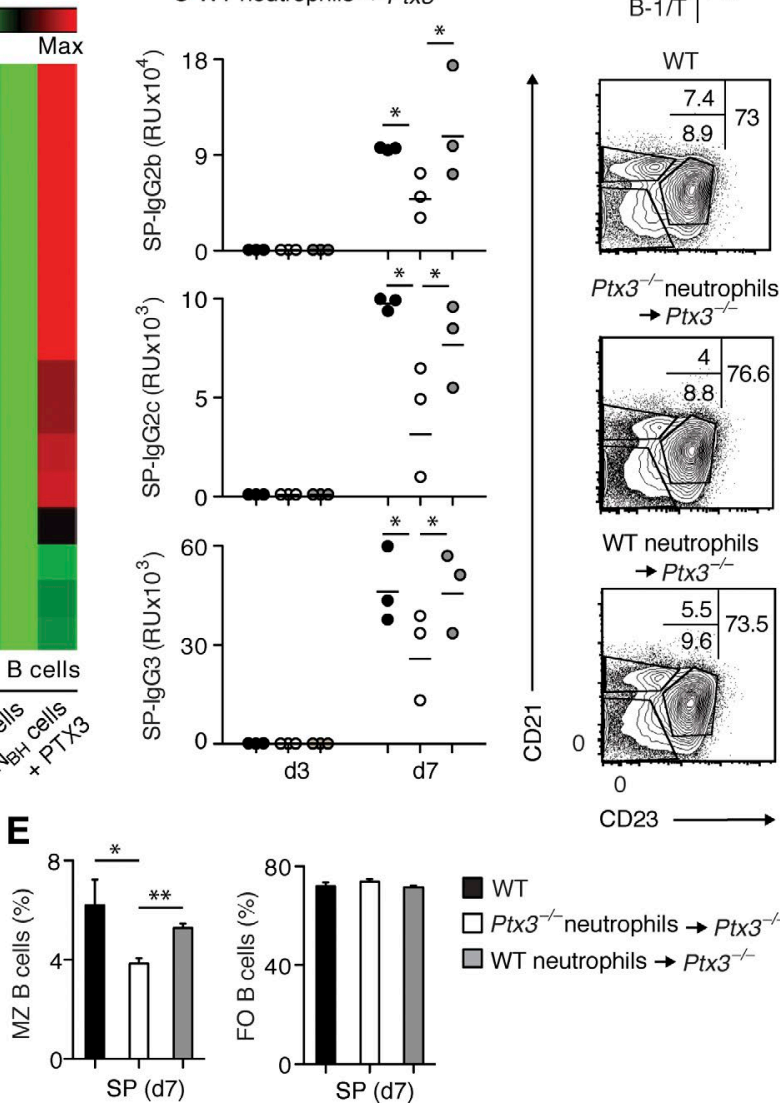

D

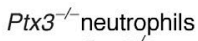
$\rightarrow P t \times 3^{-/}$

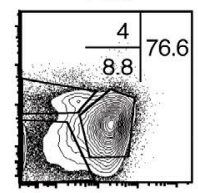

WT neutrophils $\rightarrow$ Ptx $3^{-1-}$

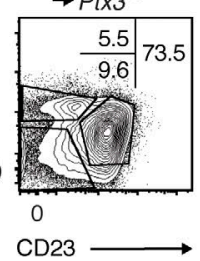

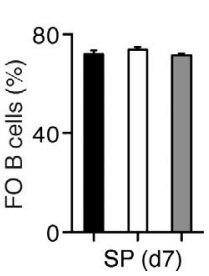

WT

$\square$ Ptx $^{-/}$neutrophils $\rightarrow P t \times 3^{-/}$

$\square$ WT neutrophils $\rightarrow \mathrm{Ptx}^{-/-}$

Figure 9. PTX3 from NBh cells delivers NF- $\mathrm{B} B$-inducing signals and elicits IgG CSR and production in MZ B cells. (A) qRT-PCR of $m R$ RAs for AID (Aicda) and $1 \gamma 2 b-C \gamma 2 b$ and ELISA of IgG2b in MZ B cells from WT mice co-cultured with or without NBh cells from WT or Ptx $3^{-/-}$mice in the presence or absence of LPS for $2 \mathrm{~d}$ (mRNAs) or $5 \mathrm{~d}(\mathrm{lgG})$. Results are normalized to mRNA for the B cell-specific molecule CD79a and presented as relative expression (RE) as compared with MZ B cells incubated with medium alone. (B) qRT-PCR array of NF- $\kappa B$-dependent gene products in MZ B cells isolated from 2-d

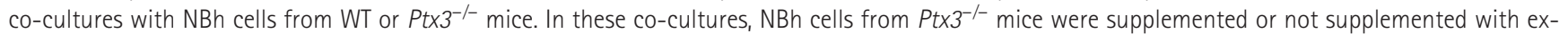
ogenous PTX3. Results are normalized to mRNA for $\beta$-actin and presented relatively to mean expression. The color code indicates high (red), mean (black), and low (green) expression. (C-E) ELISA of serum SP-specific IgG2b, IgG2c, and IgG3 (C) and flow cytometric analysis of frequencies of MZ, transitional (T)/B-1 and FO B cells (D and E) after i.v. injection of live SP in WT mice, Ptx $3^{-/-}$mice adoptively transferred with PTX3-sufficient (from WT mice) NBh cells,

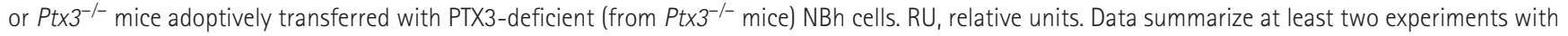
at least three mice in each experimental group (A and $\mathrm{C}-\mathrm{E}$ ) or show one representative experiment of two with similar results $(\mathrm{B})$. Error bars, $\mathrm{SEM}$. ${ }^{*}, \mathrm{P}<$ $0.05 ;{ }^{* *}, \mathrm{P}<0.01 ;{ }^{* * *}, \mathrm{P}<0.001$ (two-tailed Student's $t$ test).

immunization, neutrophil depletion did not affect TNP-specific IgM and IgG responses (Fig. 10 E). Thus, mouse PTX3 from NBh cells activates CSR from IgM to IgG by inducing $\mathrm{NF}-\kappa \mathrm{B}$-activating signals that may contribute to MZ B cell responses against TI antigens.

\section{DISCUSSION}

We have shown here that splenic neutrophils had a GMCSF-related gene signature that reflected immune activation and correlated with enhanced PTX3 release. Binding of PTX3 to MZ B cells promoted CSR followed by extrafollicular expansion of PBs and PCs secreting IgM and IgG. These effects enhanced both homeostatic and postimmune antibody responses to CPS through an innate-like pathway that did not require mandatory help from $\mathrm{T}$ cells. Thus, we propose that PTX3 links the humoral arms of the innate and adaptive immune systems by functioning as an endogenous adjuvant for MZ B cells.

Myeloid cells show phenotypic and functional heterogeneity resulting from both irreversible lineage-specific differentiation and reversible activation of tissue-specific gene programs (Gosselin et al., 2014; Lavin et al., 2014). In the gut, macrophages acquire B-1 cell helper function in response to retinoic acid, a metabolite of dietary vitamin A (Okabe and Medzhitov, 2014). In the spleen, neutrophils may acquire MZ B cell helper function in response to multiple 
A
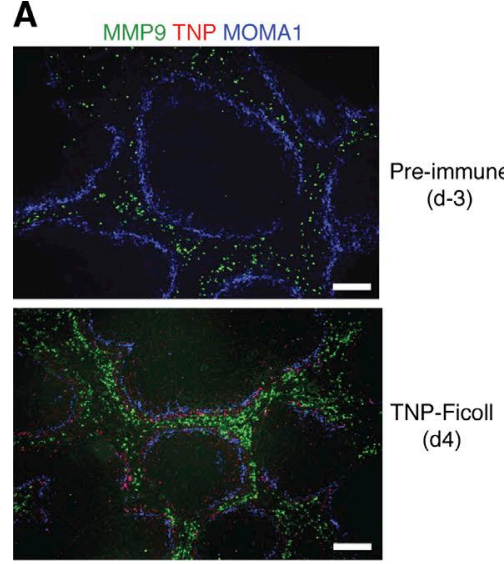

B

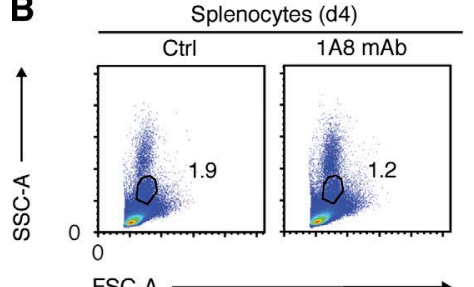

FSC-A

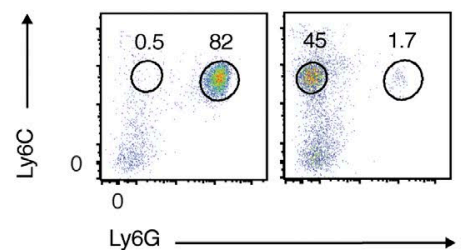

C

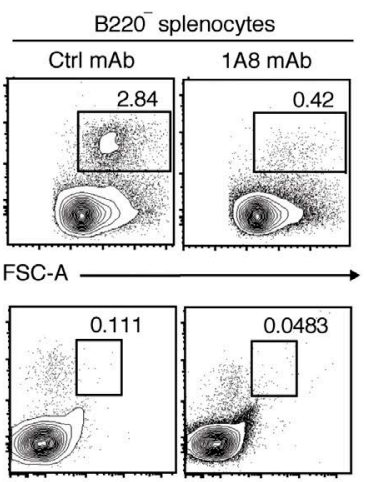

$\lg G 2 b$

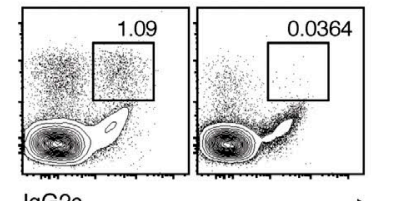

$\lg \mathrm{G} 2 \mathrm{c}$

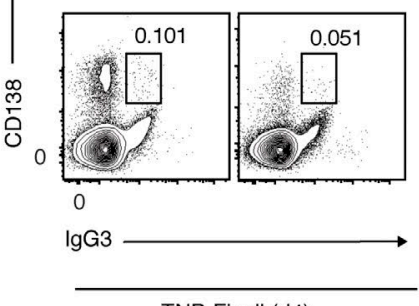
D Pre-immune $\frac{\text { TNP-Ficoll (d4) }}{\square C H A B A D}$

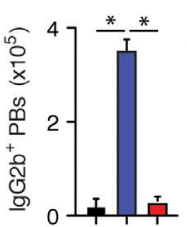

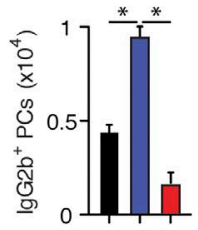
T

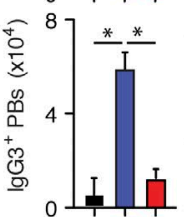

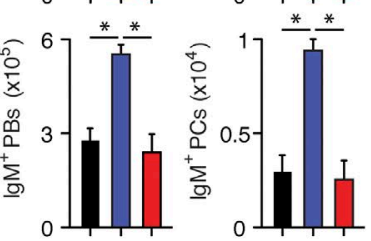

E

- Corl mAb

- 1 A8 mAb

O Late (d3) 1A8 mAb
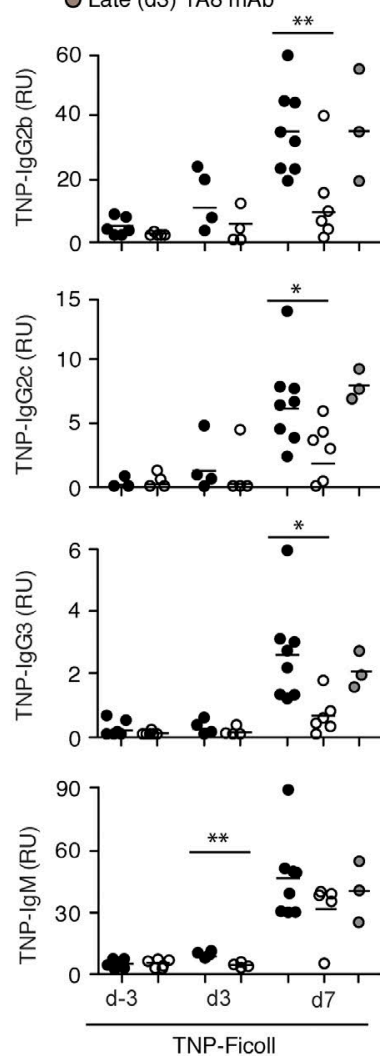

Figure 10. NBh cell depletion impairs the expansion of splenic IgG class-switched PBs and PCs after polysaccharide immunization. (A) IFA of spleens stained for MMPg (green), TNP (red), and MOMA-1 or B220 (blue) from WT mice before (d0) and after (d3) i.v. immunization with TNP-Ficoll. Bars, $100 \mu \mathrm{m}$. (B) Flow cytometric analysis of the frequency of splenic Ly6G+ Ly6C $\mathrm{C}^{+} \mathrm{NBh}$ cells and Ly6G ${ }^{\circ} \mathrm{Ly} 6 \mathrm{C}^{+}$monocytes/macrophages before and after treatment of WT mice with control (Ctrl) or 1 A8 mAbs for $3 \mathrm{~d}$. FSC, forward side scatter; SSC, side scatter. (C and D) Flow cytometric analysis of frequencies and absolute numbers of total B220-CD138 PBs/PCs and class-switched B220-CD138 ${ }^{+}$PBs/PCs expressing IgG2b, IgG2c, or IgG3 from spleens of WT mice i.v. immunized with TNP-Ficoll (d7) after continuous i.p. treatment with nonneutrophil-depleting control mAb or neutrophil-depleting $1 A 8 \mathrm{mAb}$ from day -3 before immunization to day 7 after immunization. (E) ELISA of serum TNP-specific lgG2b, IgG2c, IgG3, and IgM from WT mice treated and immunized as in A. Late $1 \mathrm{~A} 8 \mathrm{mAb}$ indicates treatment with $1 \mathrm{~A} 8 \mathrm{mAb}$ starting at day 3 instead of day -3 . RU, relative units. Data show one representative experiment of at least three with similar results ( $\mathrm{A}$ and $\mathrm{B}$ ) or summarize at least two experiments with at least four mice in each experimental group (C-E). Error bars, SEM. ${ }^{*}, \mathrm{P}<0.05{ }^{* *}, \mathrm{P}<0.01$ (two-tailed Student's $t$ test).

tissue-specific signals, including GM-CSF, a cytokine produced by group 3 ILCs (Puga et al., 2012; Magri et al., 2014). Accordingly, although largely overlapping with that of NC cells, the transcriptome of NBh cells featured a prominent GM-CSF-related immune activation signature that entailed increased expression of PTX3, a soluble antibody-like pattern recognition molecule of the innate immune system (Bottazzi et al., 2010).

Besides containing abundant transcripts for PTX3, NBh cells released large amounts of PTX3 that bound to MZ B cells. This binding occurred through a mechanism that required neither Fc $\gamma$ Rs nor TLR 4 but was augmented by C1q, a complement protein expressed by $\mathrm{NBh}$ cells as well as stromal reticular cells residing in the MZ. Given that PTX3 recruits $\mathrm{C} 1 \mathrm{q}$ and that $\mathrm{C} 1 \mathrm{q}$ augments $\mathrm{MZ} \mathrm{B}$ cell responses by promoting complement decoration of TI antigens (Guinamard et al., 2000; Kang et al., 2006; Bottazzi et al., 2010), we argue that PTX3 from NBh cells boosts innate-like antibody responses by establishing interactions with $\mathrm{C} 1 \mathrm{q}$ on opsonized TI antigens. These interactions may optimize antigen-driven BCR signals and also provide accessory signals via both PTX3 and complement receptors.

Together with B-1 cells, MZ B cells homeostatically generate antibodies to TI antigens through an innate-like pathway involving NBh cells (Ochsenbein et al., 1999; Woods et al., 2011; Puga et al., 2012; Panda et al., 2013; Magri et al., 2014). Despite showing conserved B-1 and MZ B cells, $\mathrm{Ptx}^{-1-}$ mice had reduced homeostatic IgM responses to CPS 
and other TI microbial moieties. This reduction paralleled that of CPS-reactive IgG in the lungs of humans harboring an h2/h2 haplotype impairing neutrophil expression of PTX3 (Cunha et al., 2014). In mice, loss of PTX3 correlated with attenuated MZ B cell expression of BLIMP-1, a transcription factor induced by $\mathrm{MZ} \mathrm{B}$ cells poised to undergo $\mathrm{PB} / \mathrm{PC}$ differentiation (Martin et al., 2001). Given that IgM and IgG emerging from steady-state antibody responses extensively interact with complement, collectins, and ficolins (Garlanda et al., 2002; Ma et al., 2009; Panda et al., 2013; Jaillon et al., 2014), our data suggest that PTX3 homeostatically activates MZ B cells to integrate the humoral arm of the innate immune system with an adaptive layer of fluid-phase protection.

MZ B cells and B-1 cells also mount postimmune antibody responses to encapsulated pathogens and CPS through an innate-like pathway possibly involving GM-CSF-activated NBh cells (Martin et al., 2001; Puga et al., 2012; Magri et al., 2014; Seifert et al., 2015). Accordingly, Ptx $3^{-/-}$mice showed impaired IgM and IgG production to the encapsulated pathogen SP, and this impairment correlated with reduced MZ B cell proliferation, attenuated IgM-to-IgG CSR, and decreased expansion of extrafollicular PBs and PCs secreting SP-reactive IgG. This humoral deficiency was rescued by adoptively transferring PTX3-sufficient but not PTX3-deficient NBh cells into Ptx $3^{-/-}$mice. The involvement of PTX3-expressing NBh cells was further corroborated by the observation that $P t \times 3^{-/-}$mice and neutrophil-depleted mice had a comparable impairment of MZ B cell responses to Ficoll, a polysaccharide that mimics CPS.

PTX3 promoted IgG CSR and initiated PB/PC differentiation by activating MZ B cells through a pathway that entailed up-regulation of the CSR-inducing enzyme AID, induction of BLIMP-1, and down-regulation of the BLI MP-1-inhibiting transcription factor PAX5. Induction of IgG secretion required cosignals from BAFF or IL-10, two cytokines released by splenic NBh cells, ILCs, DCs, and/or macrophages (Martin et al., 2001; Balázs et al., 2002; Puga et al., 2012; Magri et al., 2014). In agreement with data involving adoptive transfer experiments of PTX3-sufficient or PTX3-deficient NBh cells, MZ B cells produced IgG when co-cultured with NBh cells from WT but not $P t \times 3^{-/-}$mice. However, NBh cells from $P t \times 3^{-/-}$mice regained IgG-inducing activity when supplemented with exogenous PTX3.

Consistent with the pivotal role of NF- $\mathrm{KB}$ in the induction of germline $\mathrm{C} \gamma$ gene transcription and AID expression (Honjo et al., 2002), PTX3 activated an NF-кB-regulated response that involved up-regulation of gene products involved in the activation, proliferation, and survival of $\mathrm{MZ} \mathrm{B}$ cells, including CD25, XIAP, FAS, and MYC. The receptor accounting for the activation of MZ B cells by PTX3 remains elusive. Unlike myeloid cells (Bottazzi et al., 2010; Bozza et al., 2014), MZ B cells did not bind PTX3 through TLR4 and FcyRs. Though complement receptors may play an auxiliary role, recent evidence points to the involvement of lectin-like oxidized low-density lipoprotein receptor 1 (LOX-1) in the induction of CSR (Joo et al., 2014). Besides oxidized low-density lipoproteins, LOX-1 recognizes CRP (Shih et al., 2009), a PTX family member that delivers NF-кB-dependent activation signals to PCs (Yang et al., 2007). Similar to macrophages, MZ B cells express LOX-1 and undergo NF- $\mathrm{KB}$ activation and IgG CSR in response to LOX-1 engagement by poorly understood ligands that further cooperate with the innate B cell-stimulating factors BAFF and APR IL (Joo et al., 2014). Given that also PTX3 cooperated with BAFF, future studies will have to determine whether PTX3 activates MZ B cells through LOX-1.

Because of their low BCR activation threshold and elevated TLR expression (Cerutti et al., 2013), MZ B cells, B-1 cells, and even immature B cells can mount antibody responses through a TI pathway that involves CSR and perhaps some degree of SHM (Guinamard et al., 2000; Martin et al., 2001; Capolunghi et al., 2008; Puga et al., 2012; Magri et al., 2014). Accordingly, PTX3 not only bound to MZ, B-1, and immature B cells, but also enhanced IgM and class-switched IgG responses to CPS, LPS, and encapsulated bacteria in both $\mathrm{T}$ cell-sufficient and $\mathrm{T}$ cell-deficient mice, including $T \mathrm{crb}^{-/-}$ and $\mathrm{Tcrb}^{-/-} \mathrm{Pt} \times 3^{-/-}$mice.

Of note, $P t \times 3^{-1-}$ mice showed conserved $\operatorname{IgG}$ responses to the protein OVA, suggesting that PTX3 is dispensable for TD antibody production. However, consistent with recently published data indicating that PTX3 enhances humoral immunity to Neisseria meningitides (Bottazzi et al., 2015), we found that $P t \times 3^{-/-}$mice mounted weaker IgG responses to influenza virus, another pathogen recognized by PTX3 (Reading et al., 2008). A possible interpretation of this evidence is that PTX3 instigates the formation of antigen-presenting DCs via TLR4 (Bozza et al., 2014). These DCs could facilitate the differentiation of professional antibody-inducing $\mathrm{T}$ follicular helper cells, which were indeed decreased in $\mathrm{Ptx}^{-/-}$mice infected with SP, a pathogen expressing outer membrane proteins along with CPS (Colino et al., 2002). The dual TI and TD nature of B cell helper signals from PTX3 is consistent with the well known plasticity of $\mathrm{MZ} B$ cells, which can enter either TI or TD pathways to promote antibody production (Cerutti et al., 2013).

Besides mediating phagocytosis of antibody-opsonized microbes (Nathan, 2006), neutrophils may enhance antibody responses to TI antigens through various mechanisms, including BAFF (Scapini et al., 2003; Puga et al., 2012; Coquery et al., 2014; Magri et al., 2014; Seifert et al., 2015; Parsa et al., 2016). Accordingly, PTX 3 cooperated with BAFF to enhance IgG production, and mice lacking PTX3-expressing neutrophils exhibited attenuated $\operatorname{IgG}$ responses to SP. Yet, pneumococcal disease is a hallmark of B cell deficiency rather than neutropenia (Bustamante et al., 2008; Klein, 2011). This paradox may reflect the redundant nature of innate effector cells required for MZ B responses, including DCs, monocytes, macrophages, and ILCs in addition to neutrophils (Martin et al., 2001; Balázs et al., 2002; Colino et al., 2002; Kang et al., 2006; Xu et al., 2012; Giordano et al., 2014; Magri et al., 2014). 
Multiple innate effector cells may be needed to optimize the magnitude and duration of antibody responses against a wide range of encapsulated pathogens. Although somewhat dispensable in humans infected with SP, PTX3-expressing neutrophils may play a more prominent defensive role against Staphylococcus aureus, and indeed neutropenia mitigates IgG production to this microbe (Puga et al., 2012). Multiple innate signals may be also needed to finely tune the kinetics and isotypic composition of antibody responses against encapsulated bacteria. Accordingly, PTX3 deficiency decreased IgG2c and delayed IgG3 responses to SP. In summary, our findings indicate that PTX3 does not merely deploy antibody-like recognition properties, but also helps innate-like antibody production. This dual activity could be harnessed to ameliorate the immunogenicity of vaccines against encapsulated bacteria.

\section{MATERIALS AND METHODS Human subjects}

Mononuclear cells and neutrophils were isolated from the peripheral blood of healthy volunteers or histologically normal spleens from organ donors (Puga et al., 2012). BAL samples were obtained from 26 patients with confirmed diagnosis of sarcoidosis (37.2 $\pm 8.8 \mathrm{y} ; 1: 1 \mathrm{male} /$ female), who underwent BAL at the Pneumology Department of the Centro Hospitalar de S. João as part of their initial diagnostic workup (Costabel and Hunninghake, 1999). Four aliquots of $50 \mathrm{ml}$ of sterile isotonic saline solution $\left(37^{\circ} \mathrm{C}\right)$ were instilled under flexible bronchoscopy in the middle lobe and gently aspirated with a syringe after each instillation. Recovered BAL fluid was pooled, gauze-filtered, centrifuged at 1,500 rpm for $5 \mathrm{~min}$, and stored frozen at $-80^{\circ} \mathrm{C}$. The Institutional Review Board of Institut Hospital del Mar d' Investigacions Mèdiques, Icahn School of Medicine at Mount Sinai, Centro Hospitalar de S. João, and University of Minho approved the use of blood, tissue, and BAL samples.

\section{Mice}

$\mathrm{Ptx}^{-/-}$and $M y d 88^{-/-}$Trif $^{/-}$mice have been previously described (Garlanda et al., 2002; Nair-Gupta et al., 2014). $\mathrm{Tcrb}^{-/-}$mice from Charles River were crossed with $P t \times 3^{-/-}$ mice to obtain $P_{t \times} 3^{-/-} T_{c r} b^{-/-}$mice. All these mice were on a C57BL/6 background and were housed in a specific pathogen-free facility at Istituto Clinico Humanitas or Icahn School of Medicine at Mount Sinai. Both male and female mice were used at 8-12 wk of age, and experiments were performed in accordance with approved protocols from the Icahn School of Medicine at Mount Sinai or Istituto Clinico Humanitas.

\section{Cells}

Mouse splenocytes were obtained after dissociating spleens with frosted glass slides. Erythrocytes were lysed with ammonium chloride-potassium phosphate buffer.Viable leukocytes were determined by trypan blue exclusion and counted using a Neubauer chamber. B $220^{+} \mathrm{CD} 21^{\text {hi }} \mathrm{CD} 23^{\text {lo }} \mathrm{MZ} \mathrm{B}$ cells, B220 ${ }^{+} \mathrm{CD} 21^{\mathrm{lo}} \mathrm{CD} 23^{\text {hi }}$ FO B cells, and Ly6G ${ }^{\text {hi }} \mathrm{CD} 11 \mathrm{~b}{ }^{\text {hi }}$ $\mathrm{NBh}$ cells were enriched from splenocytes using an Easysep kit (STEMCELL Technologies) and further purified through FACS sorting. Human $\mathrm{CD}^{-} \mathrm{CD} 19^{-} \mathrm{CD} 16^{\text {hi }} \mathrm{NC}$ cells, CD3 ${ }^{-} \mathrm{CD} 19^{-} \mathrm{CD} 16^{\text {int }} \mathrm{NBh}$ cells, CD19 ${ }^{+} \mathrm{B}$ cells, IgD${ }^{\text {lo }} \mathrm{CD} 27^{+} \mathrm{MZ} \mathrm{B}$ cells, IgD hi CD27 ${ }^{-} \mathrm{FO} \mathrm{B}$ cells, $\mathrm{CD}^{+} \mathrm{T}$ cells, CD $14^{+}$monocytes-macrophages, CD11c ${ }^{\text {hi }}$ HLA-II ${ }^{\text {hi }}$ DCs, and $\mathrm{CD}_{16}{ }^{+} \mathrm{CD} 6^{+} \mathrm{NK}$ cells were FACS sorted (>98\% purity) as described previously (Magri et al., 2014).

\section{Microarray analysis}

RNA was extracted from FACS-sorted NC and NBh cells using a High Pure RNA Isolation kit (Roche). RNA samples were checked for purity using a spectrophotometer (ND-1000; NanoDrop Technologies) and for integrity using a BioAnalyzer (2100; Agilent Technologies). $100 \mathrm{ng}$ of total RNA was labeled using a Low Input Quick Amp Labeling kit (Agilent Technologies). Labeled cRNA was hybridized to a human gene expression $8 \times 60 \mathrm{~K}$ microarray (SurePrint G3; Agilent Technologies) according to the manufacturer's instructions. Intensity data were extracted using Feature Extraction software (Agilent Technologies). Raw data were taken from Feature Extraction output files and corrected for background noise using the normexp method. Quantile normalization was used to ensure comparability across samples. Differential expression analysis was performed on noncontrol probes with an empirical Bayes approach on linear models for microarray data. Differentially expressed genes (Table S5) were identified based on $>1.2$-fold change and adjusted p-value $<0.01$. Results were corrected for multiple testing according to the false discovery rate method. The Gene Expression Omnibus accession number for the transcriptional profiles reported in this paper is GSE63298. Functional gene categories were analyzed using the Database for Annotation Visualization and Integrated Discovery tool. Transcriptional profiles of NBh cells and GM-CSF-treated NC cells (GEO accession no. GSE40548) were compared through GSEA. Genes were considered highly expressed when up-regulated by $\geq 1.2$-fold (adjusted p-value $<0.01$ ) as compared with unstimulated NC cells.

\section{Genotyping of PTX3 polymorphisms}

Genomic DNA from the whole blood of patients with sarcoidosis was collected using the QIAamp DNA Blood Mini kit (QIAGEN). Genotyping of single nucleotide polymorphisms (SNPs; SNP database accession nos. rs2305619, rs3816527, and rs1840680) affecting the gene encoding PTX3 was performed using KASPar assays (LGC Biosearch Technologies) according to the manufacturer's instructions in a 7500 Fast qPCR system (Applied Biosystems; Thermo Fisher Scientific). Genotyping sets included randomly selected replicates of previously typed samples. Agreement between original and duplicate samples was $\geq 99 \%$ for all SNPs. Laboratory personnel were blind to the sample status. Genotype frequencies of the selected SNPs were used to derive the haplotype configuration for each gen- 
otype. h1/h1, h1/h2, and h2/h2 haplotypes were defined as previously described (Cunha et al., 2014).

\section{Culture conditions and reagents}

Mouse B cells were cultured in complete IMDM supplemented with 5\% fetal bovine serum and stimulated with 100 or $1,000 \mathrm{ng} / \mathrm{ml}$ LPS from Escherichia coli (Sigma-Aldrich) in the presence or absence of $5 \mu \mathrm{g} / \mathrm{ml}$ PTX3 (R\&D Systems), unless otherwise stated. In some experiments, B cells were co-cultured with $\mathrm{NBh}$ cells from WT or $\mathrm{Pt} \times 3^{-/-}$mice at a $1: 2$ or $1: 10$ ratio. In these co-cultures, $0.05-0.25 \times 10^{6} / \mathrm{ml}$ NBh cells were first plated with or without $100 \mathrm{ng} / \mathrm{ml}$ LPS for $4 \mathrm{~h}$, followed by incubation with $0.5 \times 10^{6} / \mathrm{ml} \mathrm{B}$ cells. Human B cells were cultured in complete RPMI medium supplemented with $10 \%$ fetal bovine serum and stimulated with $0.1,1,3,5,10,25$, or $30 \mu \mathrm{g} / \mathrm{ml}$ PTX3 (R\&D Systems), 100 ng/ml CpG ODN-2006 (InvivoGen), 500 ng/ml BAFF (Alexis), or $50 \mathrm{ng} / \mathrm{ml} \mathrm{IL-10} \mathrm{(PeproTech).} \mathrm{In} \mathrm{some} \mathrm{experi-}$ ments, B cells were co-cultured with NC cells at a 1:10 ratio. These NC cells were stimulated with or without $100 \mathrm{ng} / \mathrm{ml}$ LPS and/or $50 \mathrm{ng} / \mathrm{ml}$ GM-CSF (PeproTech). Recombinant PTX3 proteins were produced and purified from Chinese hamster ovary cells and mouse myeloma cells (Garlanda et al., 2002; Bozza et al., 2014). Limulus amebocyte lysate assays showed $<1 \mathrm{EU}$ (endotoxin unit) $/ \mu \mathrm{g}$ in PTX3 preparations.

\section{Flow cytometry and FACS sorting}

Cell suspensions were incubated with $\mathrm{Fc}$ blocking reagent and appropriate labeled $\mathrm{mAbs}$ (Tables S1 and S2) for $20 \mathrm{~min}$ at $4^{\circ} \mathrm{C}$. Dead cells were excluded with 4'-6-diamidine-2'-phenylindole (Boehringer Ingelheim) or 7-amino-actinomycin (BioLegend). To costain extracellular and intracellular Igs, mouse splenocytes were incubated with labeled mAbs to specific surface molecules including extracellular Igs (Table S2), permeabilized, fixed with a Cytofix/Cytoperm kit (BD), and further incubated with labeled mAbs to specific intracellular Igs (Table S2). Cells were acquired with an LSRFortessa flow cytometer or sorted with FACSAria II flow cytometer (BD), and data were analyzed with Flowjo software (Tree Star).

\section{Tissue IFA}

Frozen tissues and cells from humans or mice were fixed as reported in previous studies (Puga et al., 2012; Magri et al., 2014) and stained with labeled mAbs (Tables S1 and S2). In mouse experiments, spleen processing was preceded by perfusion to eliminate blood cells from tissue. Biotin-conjugated mAbs were detected with streptavidin-conjugated Alexa Fluor 488, 546, or 647 (Thermo Fisher Scientific). Nuclear DNA was stained with DAPI. Coverslips were applied with FluorSave reagent (EMD Millipore). Images were obtained with a microscope (Axioplan2; ZEISS) and further analyzed with AxioVision software (ZEISS). Confocal images were generated with a TCS SPE inverted confocal microscope (Leica Biosystems) by the acquisition of at least 12 different $z$ planes (ZEISS) with $z$ spacing of $0.3 \mu \mathrm{m}$.

\section{ELISA}

Total human and mouse $\operatorname{IgM}$, IgG, and IgA were detected in M96-Nunc ELISA plates as reported in published studies (Puga et al., 2012; Magri et al., 2014). To measure antigen-specific antibody responses, plates were coated overnight with 10 $\mu \mathrm{g} / \mathrm{ml}$ relevant antigen in $\mathrm{PBS}$ at $4^{\circ} \mathrm{C}$, washed three times with PBS and $0.1 \%$ Tween 20 (Thermo Fisher Scientific), blocked for $2 \mathrm{~h}$ at room temperature with PBS and 1\% BSA or $5 \%$ nonfat milk, and washed three times. To capture antigen-specific antibodies, plates were first incubated overnight at $4^{\circ} \mathrm{C}$ with appropriately diluted sera and washed five times before incubation for $1 \mathrm{~h}$ at $37^{\circ} \mathrm{C}$ with HRP-conjugated goat anti-mouse detection antibody (SouthernBiotech). After seven additional washes, reactions developed with the HRP substrate $3^{\prime}, 5,5^{\prime}$-tetramethylbenzidine were stopped using $2 \mathrm{~N} \mathrm{H}_{2} \mathrm{SO}_{4}$. The relative concentration of antigen-specific antibodies in serum from immunized mice was expressed in arbitrary ELISA relative units calculated from a standard curve obtained with hyperimmune serum. An appropriate control serum was used as standard to quantify total antibody concentrations. Finally, PTX3 was detected using a mouse ELISA kit (Pentraxin 3/TSG-14 Quantikine) and a human ELISA kit (Pentraxin 3/TSG-14 Quantikine; R\&D Systems).

\section{ELISPOT}

0.45- $\mu \mathrm{m}$ ELISPOT plates (MultiScreen HTS IP; Millipore) were coated with $5 \mu \mathrm{g} / \mathrm{ml}$ antigen in PBS. The next day, plates were washed twice with RPMI 1640 medium and blocked with $10 \%$ FCS in RPMI 1640 at $37^{\circ} \mathrm{C}$ for $2 \mathrm{~h}$. Splenocytes were added to the wells and incubated overnight at $37^{\circ} \mathrm{C}$ and $5 \% \mathrm{CO}_{2}$. The next day, cells were discarded, and plates were washed twice with deionized $\mathrm{H}_{2} \mathrm{O}$ and three times with $0.1 \%$ Tween in PBS. Antigen-specific antibody spots were detected by adding a detection HRP-conjugated goat anti-mouse antibody and AEC Substrate set (BD). Color development was stopped by washing several times with water. Plates were scanned, and spots were counted with an ImmunoSpot microanalyzer (Cellular Technology Limited).

\section{Binding assays}

Control BSA and mouse or human PTX3 were labeled with either Alexa Fluor 647 or Alexa Fluor 488 (Molecular Probes). Human peripheral blood mononuclear cells or mouse splenocytes were incubated with different concentrations of labeled protein for $20 \mathrm{~min}$ at $4^{\circ} \mathrm{C}$, washed, and stained with $\mathrm{B}$ cell-specific mAbs to generate appropriate electronic gates. Blocking experiments were performed by exposing cells with $30 \mu \mathrm{g} / \mathrm{ml}$ of unlabeled PTX3 or control $\operatorname{IgG}$ for $10 \mathrm{~min}$ before incubation with labeled PTX3.

\section{PCRs and Southern blotting}

RNA was extracted and reversed transcribed into cDNA as previously described in published studies (Puga et al., 2012; Magri et al., 2014). Germline and switch circle transcripts were amplified by standard reverse transcription PCR and 
hybridized with appropriate radiolabeled probes as previously reported in published works (Puga et al., 2012; Magri et al., 2014). For the quantification of human or mouse gene products, total RNA was extracted and reverse transcribed into cDNA as previously described (Puga et al., 2012; Magri et al., 2014). qRT-PCRs were performed using specific primer pairs (Tables S3 and S4). Specific gene expression was normalized to that of genes encoding the house keeping proteins $\beta$-actin and hypoxanthine-guanine phosphoribosyl transferase (HPRT) or the B cell-specific protein CD79a.

\section{Immunizations and infections}

Mice were i.v. or i.p. immunized with $5 \mu \mathrm{g}$ TNP-Ficoll, 5 $\mu \mathrm{g}$ TNP-LPS (LGC Biosearch Technologies), $2.87 \mu \mathrm{g}$ Pneumovax 23 (Merck), or $50 \mu \mathrm{g}$ NP-OVA supplemented with alum (LGC Biosearch Technologies). Mice were also i.v. infected with $2 \times 10^{7}$ SP (CPS-14) or i.n. infected with 100 PFU mouse-adapted human influenza virus $\mathrm{A} / \mathrm{PR} / 8 / 34$ (PR8). In some experiments, SP was treated with mitomycin to inhibit bacterial proliferation. Lung tissue was processed to determine viral titers by plaque-forming assays.

\section{Neutrophil depletion}

$250 \mu \mathrm{g}$ of control VL-4 mAb (Bio X Cell) or $250 \mu \mathrm{g}$ of neutrophil-depleting $1 \mathrm{~A} 8 \mathrm{mAb}$ to Ly6G (Bio X Cell) were i.p. injected every other day. Injections started $3 \mathrm{~d}$ before immunization and continued until day 7 .

\section{Adoptive transfer}

$2 \times 10^{6}$ neutrophils from the bone marrow of WT or Ptx $3^{-/-}$ mice were adoptively transferred into $P t \times 3^{-/-}$mice through tail vein injection $4 \mathrm{~h}$ after exposure to SP. Neutrophils were tracked in the spleen by flow cytometry after staining them with a CellTrace CFSE Cell Proliferation kit (Invitrogen).

\section{Statistical analysis}

Statistical significance was assessed with a two-tailed or onetailed unpaired Student's $t$ test, unless specified otherwise. A Mann-Whitney $U$ test or Wilcoxon matched-pairs signedrank test was used for analysis of nonparametric data. Results were analyzed with Prism (GraphPad Software), and p-values of $<0.05$ were considered significant. In animal experiments, at least three mice per group were randomly distributed into treatment groups so that all groups were age matched and sex matched. No specific randomization or blinding protocol was used, and no animals were excluded from analysis.

\section{Online supplemental material}

Fig. S1 validates the surface phenotype and PTX3 expression levels of human NBh cells. Fig. S2 shows the strategy to sort mouse $\mathrm{NBh}$ cells and the efficiency of adoptive transfer experiments involving control or PTX3-deficient NBh cells. Table S1 lists antibodies to human antigens. Table S2 lists antibodies to mouse antigens. Tables S3 and S4 list primers used to PCR amplify mouse and human gene products, respectively. Table S5 lists genes from NBh cells with the highest degree of differential expression compared with $\mathrm{NC}$ cells. Online supplemental material is available at http:// www.jem.org/cgi/content/full/jem.20150282/DC1.

\section{ACKNOWLEDGMENTS}

This study was supported by European Advanced grant ERC-2011-ADG-20110310, Ministerio de Ciencia e Innovación grant SAF2011-25241, and Marie Curie reintegration grant PIRG-08-GA-2010-276928 to A. Cerutti; Sara Borrell post-doctoral fellowships to A. Chorny; and US National Institutes of Health grants R01 Al57653, U01 Al95613, P01 Al61093, and U19 096187 to A. Cerutti. C. Cunha and A. Carvalho were funded by grants from Fundação para a Ciência e Tecnologia, co-funded by Programa Operacional Regional do Norte (ON.2-O Novo Norte)., and from the Quadro de Referência Estratégico Nacional (SFRH/BPD/96176/2013 to C. Cunha and grant IF/00735/2014 to A. Carvalho) through the Fundo Europeu de Desenvolvimento Regional and Projeto Estratégico (LA 26 - 2013-2014; PEst-C/SAU/LA0026/2013). The financial support of the European Commission (FP7-HEALTH-2011-ADITEC-No.280873 and ERC-PHII-669415) to A. Mantovani is gratefully acknowledged.

The authors declare no competing financial interests.

Author contributions: A. Chorny designed and performed research, discussed data, and wrote the paper. S. Casas-Recasens, N. Polentarutti, J. Sintes, M. Shan, L. Cassis, J. Carrillo, I. Puga, and R. Dieguez-Gonzalez performed research. R. Garcia-Escudero analyzed microarray data. P.S. Heeger, G. Salvatori, and J.M. Blander helped with mouse models and PTX3 reagents and discussed data. A. Garcia-Sastre helped with experiments involving PR8 influenza virus and discussed data. C. Cunha, H. Bastos, F. Rodrigues, J.F. Lacerda, and A. Morais genotyped h1/h1, h1/h2, and h2/h2 haplotypic variants and collected BAL fluids. A. Carvalho designed researched, provided BAL samples, and discussed data. A. Mantovani discussed data. C. Garlanda designed research, generated PTX3 reagents, and discuss data. A. Cerutti designed research, discussed data, and wrote the paper.

Submitted: 13 February 2015

Accepted: 4 August 2016

\section{REFERENCES}

Balázs, M., F. Martin, T. Zhou, and J. Kearney. 2002. Blood dendritic cells interact with splenic marginal zone $\mathrm{B}$ cells to initiate T-independent immune responses. Immunity. 17:341-352. http://dx.doi.org/10.1016/ S1074-7613(02)00389-8

Bottazzi, B., A. Doni, C. Garlanda, and A. Mantovani. 2010. An integrated view of humoral innate immunity: pentraxins as a paradigm. Annu. Rev. Immunol. 28:157-183. http://dx.doi.org/10.1146/annurev-immunol -030409-101305

Bottazzi, B., L. Santini, S. Savino, M.M. Giuliani, A.I. Dueñas Díez, G. Mancuso, C. Beninati, M. Sironi, S. Valentino, L. Deban, et al. 2015. Recognition of Neisseria meningitidis by the long pentraxin PTX3 and its role as an endogenous adjuvant. PLoS One. 10:e0120807. http://dx .doi.org/10.1371/journal.pone.0120807

Bozza, S., S. Campo, B. Arseni, A. Inforzato, L. Ragnar, B. Bottazzi, A. Mantovani, S. Moretti, V. Oikonomous, R. De Santis, et al. 2014. PTX3 binds MD-2 and promotes TRIF-dependent immune protection in aspergillosis. J. Immunol. 193:2340-2348. http://dx.doi.org/10.4049/ jimmunol.1400814

Bustamante, J., S. Boisson-Dupuis, E. Jouanguy, C. Picard, A. Puel, L. Abel, and J.L. Casanova. 2008. Novel primary immunodeficiencies revealed by the investigation of paediatric infectious diseases. Curr. Opin. Immunol. 20:39-48. http://dx.doi.org/10.1016/j.coi.2007.10.005

Capolunghi, F., S. Cascioli, E. Giorda, M.M. Rosado, A. Plebani, C. Auriti, G. Seganti, R. Zuntini, S. Ferrari, M. Cagliuso, et al. 2008. CpG drives human transitional B cells to terminal differentiation and production of natural antibodies. J. Immunol. 180:800-808. http://dx.doi.org/10.4049 /jimmunol.180.2.800 
Cerutti, A., M. Cols, and I. Puga. 2013. Marginal zone B cells: virtues of innate-like antibody-producing lymphocytes. Nat. Rev. Immunol. 13:118-132. http://dx.doi.org/10.1038/nri3383

Colino, J.,Y. Shen, and C.M. Snapper. 2002. Dendritic cells pulsed with intact Streptococcus pneumoniae elicit both protein- and polysaccharidespecific immunoglobulin isotype responses in vivo through distinct mechanisms. J. Exp. Med. 195:1-14. http://dx.doi.org/10.1084/jem .20011432

Coquery, C.M., N.S. Wade, W.M. Loo, J.M. Kinchen, K.M. Cox, C. Jiang, K.S. Tung, and L.D. Erickson. 2014. Neutrophils contribute to excess serum BAFF levels and promote $\mathrm{CD}^{+} \mathrm{T}$ cell and $\mathrm{B}$ cell responses in lupusprone mice. PLoS One. 9:e102284. http://dx.doi.org/10.1371/journal .pone. 0102284

Costabel, U., and G.W. Hunninghake. Sarcoidosis Statement Committee. American Thoracic Society. European Respiratory Society. World Association for Sarcoidosis and Other Granulomatous Disorders. 1999. ATS/ERS/WASOG statement on sarcoidosis. Eur. Respir. J. 14:735-737. http://dx.doi.org/10.1034/j.1399-3003.1999.14d02.x

Cunha, C., F. Aversa, J.F. Lacerda, A. Busca, O. Kurzai, M. Grube, J. Löffler, J.A Maertens, A.S. Bell, A. Inforzato, et al. 2014. Genetic PTX3 deficiency and aspergillosis in stem-cell transplantation. N. Engl. J. Med. 370:421432. http://dx.doi.org/10.1056/NEJMoa1211161

Ehrenstein, M.R., and C.A. Notley. 2010. The importance of natural IgM: scavenger, protector and regulator. Nat. Rev. Immunol. 10:778-786. http ://dx.doi.org/10.1038/nri2849

Garlanda, C., E. Hirsch, S. Bozza, A. Salustri, M. De Acetis, R. Nota, A. Maccagno, F. Riva, B. Bottazzi, G. Peri, et al. 2002. Non-redundant role of the long pentraxin PTX3 in anti-fungal innate immune response. Nature. 420:182-186. http://dx.doi.org/10.1038/nature01195

Giordano, D., K.E. Draves, C. Li, T.M. Hohl, and E.A. Clark. 2014. Nitric oxide regulates BAFF expression and $\mathrm{T}$ cell-independent antibody responses. J. Immunol. 193:1110-1120. http://dx.doi.org/10.4049/ jimmunol.1303158

Gosselin, D., V.M. Link, C.E. Romanoski, G.J. Fonseca, D.Z. Eichenfield, N.J. Spann, J.D. Stender, H.B. Chun, H. Garner, F. Geissmann, and C.K. Glass. 2014. Environment drives selection and function of enhancers controlling tissue-specific macrophage identities. Cell. 159:1327-1340. http://dx.doi.org/10.1016/j.cell.2014.11.023

Guinamard, R., M. Okigaki, J. Schlessinger, and J.V. Ravetch. 2000. Absence of marginal zone B cells in Pyk-2-deficient mice defines their role in the humoral response. Nat. Immunol. 1:31-36.

Holmskov, U., S. Thiel, and J.C. Jensenius. 2003. Collections and ficolins: humoral lectins of the innate immune defense. Annu. Rev. Immunol. 21:547-578. http://dx.doi.org/10.1146/annurev.immunol.21.120601 .140954

Honjo, T., K. Kinoshita, and M. Muramatsu. 2002. Molecular mechanism of class switch recombination: linkage with somatic hypermutation. Annu. Rev. Immunol. 20:165-196. http://dx.doi.org/10.1146/annurev .immunol.20.090501.112049

Jaillon, S., G. Peri, Y. Delneste, I. Frémaux, A. Doni, F. Moalli, C. Garlanda, L. Romani, H. Gascan, S. Bellocchio, et al. 2007. The humoral pattern recognition receptor PTX3 is stored in neutrophil granules and localizes in extracellular traps. J. Exp. Med. 204:793-804. http://dx.doi.org/10 $.1084 / \mathrm{jem} .20061301$

Jaillon, S., F. Moalli, B. Ragnarsdottir, E. Bonavita, M. Puthia, F. Riva, E. Barbati, M. Nebuloni, L. Cvetko Krajinovic, A. Markotic, et al. 2014. The humoral pattern recognition molecule PTX3 is a key component of innate immunity against urinary tract infection. Immunity. 40:621-632. http://dx.doi.org/10.1016/j.immuni.2014.02.015

Joo, H., D. Li, M. Dullaers, T.W. Kim, D. Duluc, K. Upchurch, Y. Xue, S Zurawski, R. Le Grand, Y.J. Liu, et al. 2014. C-type lectin-like receptor LOX-1 promotes dendritic cell-mediated class-switched B cell responses. Immunity. 41:592-604. http://dx.doi.org/10.1016/j.immuni .2014.09.009

Kang,Y.S.,Y. Do, H.K. Lee, S.H. Park, C. Cheong, R.M. Lynch, J.M. Loeffler, R.M. Steinman, and C.G. Park. 2006. A dominant complement fixation pathway for pneumococcal polysaccharides initiated by SIGN-R1 interacting with C1q. Cell. 125:47-58. http://dx.doi.org/10.1016/j.cell .2006 .01 .046

Klein, C. 2011. Genetic defects in severe congenital neutropenia: emerging insights into life and death of human neutrophil granulocytes. Annu. Rev. Immunol. 29:399-413. http://dx.doi.org/10.1146/annurev-immunol $-030409-101259$

Lavin, Y., D. Winter, R. Blecher-Gonen, E. David, H. Keren-Shaul, M. Merad, S. Jung, and I. Amit. 2014. Tissue-resident macrophage enhancer landscapes are shaped by the local microenvironment. Cell. 159:13121326. http://dx.doi.org/10.1016/j.cell.2014.11.018

Ma,Y.J.,A. Doni, T. Hummelshøj, C. Honoré, A. Bastone, A. Mantovani, N.M. Thielens, and P. Garred. 2009. Synergy between ficolin-2 and pentraxin 3 boosts innate immune recognition and complement deposition. J. Biol. Chem. 284:28263-28275. http://dx.doi.org/10.1074/jbc.M109.009225

Magri, G., M. Miyajima, S. Bascones, A. Mortha, I. Puga, L. Cassis, C.M. Barra, L. Comerma, A. Chudnovskiy, M. Gentile, et al. 2014. Innate lymphoid cells integrate stromal and immunological signals to enhance antibody production by splenic marginal zone B cells. Nat. Immunol. 15:354-364. http://dx.doi.org/10.1038/ni.2830

Martin, F., A.M. Oliver, and J.F. Kearney. 2001. Marginal zone and B1 B cells unite in the early response against $\mathrm{T}$-independent blood-borne particulate antigens. Immunity. 14:617-629. http://dx.doi.org/10.1016 /S1074-7613(01)00129-7

McHeyzer-Williams, M., S. Okitsu, N. Wang, and L. McHeyzer-Williams. 2012. Molecular programming of B cell memory. Nat. Rev. Immunol. 12:24-34

Moalli, F., A. Doni, L. Deban, T. Zelante, S. Zagarella, B. Bottazzi, L. Romani, A. Mantovani, and C. Garlanda. 2010. Role of complement and Fc $\gamma$ receptors in the protective activity of the long pentraxin PTX3 against Aspergillus fumigatus. Blood. 116:5170-5180. http://dx.doi.org/10 .1182/blood-2009-12-258376

Nair-Gupta, P., A. Baccarini, N. Tung, F. Seyffer, O. Florey, Y. Huang, M. Banerjee, M. Overholtzer, P.A. Roche, R. Tampé, et al. 2014. TLR signals induce phagosomal MHC-I delivery from the endosomal recycling compartment to allow cross-presentation. Cell. 158:506-521. http://dx .doi.org/10.1016/j.cell.2014.04.054

Nathan, C. 2006. Neutrophils and immunity: challenges and opportunities. Nat. Rev. Immunol. 6:173-182. http://dx.doi.org/10.1038/nri1785

Ochsenbein, A.F., T. Fehr, C. Lutz, M. Suter, F. Brombacher, H. Hengartner, and R.M. Zinkernagel. 1999. Control of early viral and bacterial distribution and disease by natural antibodies. Science. 286:2156-2159. http://dx.doi.org/10.1126/science.286.5447.2156

Okabe,Y., and R. Medzhitov. 2014. Tissue-specific signals control reversible program of localization and functional polarization of macrophages. Cell. 157:832-844. http://dx.doi.org/10.1016/j.cell.2014.04.016

Panda, S., J. Zhang, N.S. Tan, B. Ho, and J.L. Ding. 2013. Natural IgG antibodies provide innate protection against ficolin-opsonized bacteria. EMBO J. 32:2905-2919. http://dx.doi.org/10.1038/emboj.2013.199

Parsa, R., H. Lund,A.-M. Georgoudaki, X.-M. Zhang,A.O. Guerreiro-Cacais, D. Grommisch, A. Warnecke, A.L. Croxford, M. Jagodic, B. Becher, et al. 2016. BAFF-secreting neutrophils drive plasma cell responses during emergency granulopoiesis. J. Exp. Med. 213:1537-1553. http://dx.doi .org/10.1084/jem.20150577

Puga, I., M. Cols, C.M. Barra, B. He, L. Cassis, M. Gentile, L. Comerma, A. Chorny, M. Shan, W. Xu, et al. 2012. B cell-helper neutrophils stimulate the diversification and production of immunoglobulin in the marginal 
zone of the spleen. Nat. Immunol. 13:170-180. http://dx.doi.org/10 $.1038 /$ ni.2194

Reading, P.C., S. Bozza, B. Gilbertson, M. Tate, S. Moretti, E.R. Job, E.C. Crouch, A.G. Brooks, L.E. Brown, B. Bottazzi, et al. 2008. Antiviral activity of the long chain pentraxin PTX3 against influenza viruses. J. Immunol. 180:3391-3398. http://dx.doi.org/10.4049/jimmunol.180.5 .3391

Scapini, P., B. Nardelli, G. Nadali, F. Calzetti, G. Pizzolo, C. Montecucco, and M.A. Cassatella. 2003. G-CSF-stimulated neutrophils are a prominent source of functional BLyS. J. Exp. Med. 197:297-302. http://dx.doi.org /10.1084/jem.20021343

Seifert, M., M. Przekopowitz, S. Taudien, A. Lollies, V. Ronge, B. Drees, M. Lindemann, U. Hillen, H. Engler, B.B. Singer, and R. Küppers. 2015. Functional capacities of human IgM memory B cells in early inflammatory responses and secondary germinal center reactions. Proc. Natl. Acad. Sci. USA. 112:E546-E555. http://dx.doi.org/10.1073/pnas .1416276112

Shih, H.H., S. Zhang, W. Cao, A. Hahn, J.Wang, J.E. Paulsen, and D.C. Harnish. 2009. CRP is a novel ligand for the oxidized LDL receptor LOX-1. Am J. Physiol. Heart Circ. Physiol. 296:H1643-H1650. http://dx.doi.org/10 .1152/ajpheart.00938.2008
Victora, G.D., and M.C. Nussenzweig. 2012. Germinal centers. Annu. Rev. Immunol. 30:429-457. http://dx.doi.org/10.1146/annurev-immunol $-020711-075032$

Woods, K.M., M.R. Pope, S.M. Hoffman, and S.D. Fleming. 2011. CR2 ${ }^{+}$ marginal zone $\mathrm{B}$ cell production of pathogenic natural antibodies is $\mathrm{C} 3$ independent. J. Immunol. 186:1755-1762. http://dx.doi.org/10.4049/ jimmunol.1002059

Wright, H.L., H.B. Thomas, R.J. Moots, and S.W. Edwards. 2013. RNAseq reveals activation of both common and cytokine-specific pathways following neutrophil priming. PLoS One. 8:e58598. http://dx.doi.org /10.1371/journal.pone.0058598

Xu, W., H. Joo, S. Clayton, M. Dullaers, M.C. Herve, D. Blankenship, M.T. De La Morena, R. Balderas, C. Picard, J.L. Casanova, et al. 2012. Macrophages induce differentiation of plasma cells through CXCL10/IP-10. J. Exp. Med. 209:1813-1823. http://dx.doi.org/10.1084/jem.20112142

Yang, J., M. Wezeman, X. Zhang, P. Lin, M. Wang, J. Qian, B. Wan, L. W. Kwak, L. Yu, and Q.Yi. 2007. Human C-reactive protein binds activating Fc $\gamma$ receptors and protects myeloma tumor cells from apoptosis. Cancer Cell. 12:252-265. http://dx.doi.org/10.1016/j.ccr.2007.08.008 